Research Article

\title{
Characterisation of Portuguese RC Precast Industrial Building Stock
}

\author{
H. Rodrigues $\mathbb{D},{ }^{1}$ R. Sousa $\mathbb{D}^{\circ},{ }^{2}$ H. Vitorino, ${ }^{1}$ N. Batalha, ${ }^{3}$ H. Varum $\left(\mathbb{D},{ }^{3}\right.$ and P. Fernandes $\mathbb{D}^{4}$ \\ ${ }^{1}$ RISCO, Civil Engineering Department, University of Aveiro, Aveiro, Portugal \\ ${ }^{2}$ CDRSP, Polytechnic Institute of Leiria, Leiria, Portugal \\ ${ }^{3}$ CONSTRUCT-LESE, Faculty of Engineering (FEUP), University of Porto, Porto, Portugal \\ ${ }^{4}$ CERIS, ESTG-Polytechnic Institute of Leiria, Leiria, Portugal \\ Correspondence should be addressed to H. Rodrigues; hrodrigues@ua.pt
}

Received 2 January 2020; Revised 1 July 2020; Accepted 20 July 2020; Published 8 August 2020

Academic Editor: Zaobao Liu

Copyright $\odot 2020 \mathrm{H}$. Rodrigues et al. This is an open access article distributed under the Creative Commons Attribution License, which permits unrestricted use, distribution, and reproduction in any medium, provided the original work is properly cited.

\begin{abstract}
The construction of a vulnerability model requires reliable information on the features of the buildings in the study. The purpose of this work is the characterisation of the precast industrial buildings in Portuguese industrial park, based on the survey of 73 design projects of existing buildings. The collected data are based on a previous study on the features that influence the seismic response of this type of buildings. The parameters collected are associated with the global geometry and specific elements characteristics (e.g., column dimensions, reinforcement ratios, and connections details), to the mechanical properties of the materials and other parameters that can give some important information in the characterisation of the buildings (e.g., construction year and localization). In the end, a comparison with other available databases, namely, from Italy and Turkey, is done in order to conclude about the similarity. This information is important to define representative experimental specimens and numerical simulation to conduce seismic risk analysis.
\end{abstract}

\section{Introduction}

The development of seismic risk studies requires the knowledge of the building characteristics of a given typology under analysis. The information of geometric and mechanical parameters allows the definition of reliable numerical models that can be used to derive fragility functions capable of describing the relation between the seismic intensity and building limit states.

Contrarily to what is observed for residential buildings, limited information is available in regard to the properties of precast buildings. To the authors' knowledge, in Portugal, only the study developed for the European Commission [1] presents a general description of the main typologies of the industrial building stock, but its information is insufficient to enable the development of representative numerical models.

To overcome the previous limitation, a survey was carried out analysing the structural design project of dozens of industrial reinforced concrete (RC) buildings built in the Portuguese continental territory over the last 50 years. The statistical analysis of the information gathered provides indication on the material properties as well as the geometry typically used in industrial precast RC buildings.

The present work provides the statistics associated with the properties that influence the seismic performance of these buildings. The information collected enabled the characterisation of the global geometry and the mechanical properties of the materials, as well as other local systems that may influence the seismic response of these buildings, such as columns size and reinforcement ratios, beam-to-column connection, and cladding systems.

The results obtained were also compared against previous studies conducted in Italy [2] and Turkey [3], allowing the identification of common structural characteristics. The analysis of previous studies is also important to assess the possibility to derive common properties for the Mediterranean countries and assess the possibility to use common 
database that can be used to define representative experimental specimens and numerical simulation to conduce seismic risk analysis.

\section{Portuguese Industrial Building Stock}

This report attempts to identify and quantify the main structural properties of the RC precast buildings in Portugal. Considering that these buildings represent only a fraction of the total industrial facilities in Portugal, it appears important to put this typology in perspective within the Portuguese industrial reality.

The study carried out for the European Commission [1] presents a general description of the main characteristics of the industrial building stock in Europe. Despite being mainly focused on prefabricated steel structures, this report provides also important indications on the overall characteristics of the industrial building stock, which includes RC precast buildings. As regards the buildings typologies, Figure 1 indicates that RC precast structures represent about $1 / 3$ of the total industrial park in Portugal.

Despite not being directly linked to the buildings characteristics, the type of activity developed (Figure 2) provides an indication on the size of the buildings and type of load admitted in the design process, which may condition the size of the structural elements. For example, in heavy industries, the presence of large capacity cranes is expected, as opposed to what is expected, for example, in warehousing buildings.

Following the previous comment, it is not surprising to observe that the majority of the industrial buildings have only one bay along the main direction (assumed as longitudinal direction) and that in only 9\% of the cases the buildings feature 3 or more spans (Figure 3).

Regarding the main geometrical properties, Figure 4 shows that the majority of buildings have a main span length between 20 and $30 \mathrm{~m}$, whilst, along the transverse direction, the distance between two consecutive frames is essentially between 5 and $7 \mathrm{~m}$. Finally, in terms of columns height, the study reveals that typically this varies between 6 and $8 \mathrm{~m}$ (Figure 5).

\section{Characteristics of RC Precast Buildings in Portugal}

3.1. Overview. The database presented in this chapter was built based on the information collected after analysing 73 design projects of existing RC precast buildings in the Portuguese mainland. The identification of the buildings sought to reflect an adequate geographical and temporal representation. Regarding the geographical distribution, Figure 6 shows a comparison between the location of the collected projects and the actual manufacturing industry according to the data available in Pordata [4]. The figure shows that, in both images, the buildings tend to be concentrated at the centre and northern regions of the Portuguese coast side.

Regarding the construction period, the buildings analysed were built over the last 50 years showing a clear

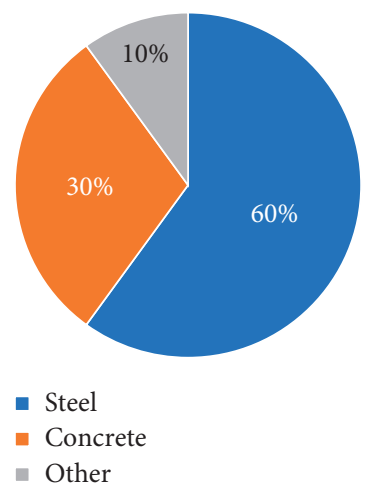

Figure 1: Structural typologies found in Portugal [1].

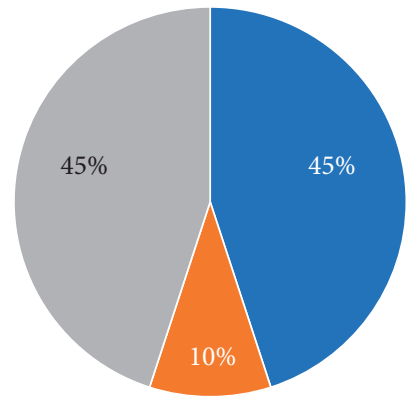

$$
\begin{aligned}
& \text { Light industrial } \\
& \text { Heavy industrial } \\
& \text { Warehousing }
\end{aligned}
$$

FIgure 2: Main activities performed in the industrial buildings in Portugal.

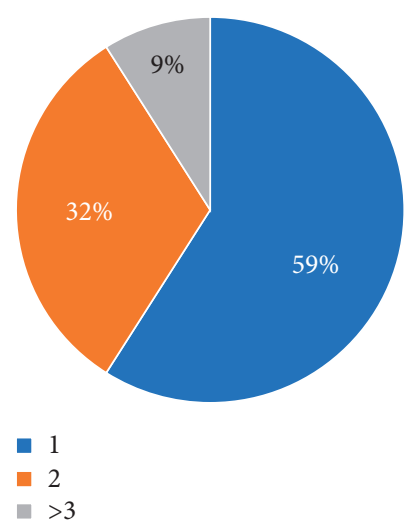

Figure 3: Number of bays in industrial buildings.

concentration after 1990 (Figure 7(a)). A first reason for this concentration is related with the very limited, or absent, information in the design project of older buildings. Moreover, until the 60s, the precast industry in Portugal was mainly focused on the construction of elements for slabs and cladding panels. It was only during the 70 s that an important growth in the precast systems could be observed [5]. Figure $7(\mathrm{~b})$ shows also the correlation between the year of construction and the seismic zones, showing that, for the buildings consulted, there is a tendency for a concentration 


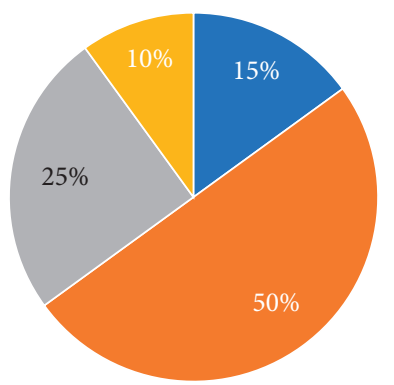

- $<20 \mathrm{~m}$

- $20-25 \mathrm{~m}$
- $25-30 \mathrm{~m}$

$>30 \mathrm{~m}$

(a)

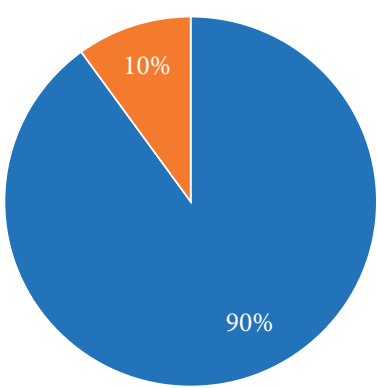

- $5-7 \mathrm{~m}$

- $>7 \mathrm{~m}$

(b)

FIgURE 4: Span length in the (a) longitudinal and (b) transverse directions.

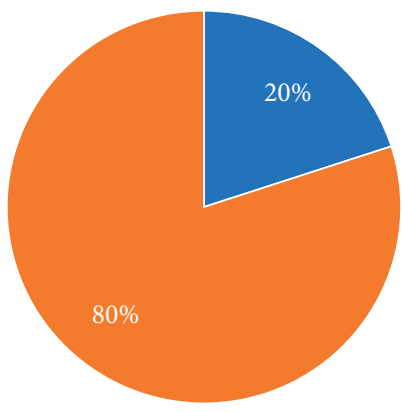

- $<6 \mathrm{~m}$

$6-8 \mathrm{~m}$

Figure 5: Height of the columns.

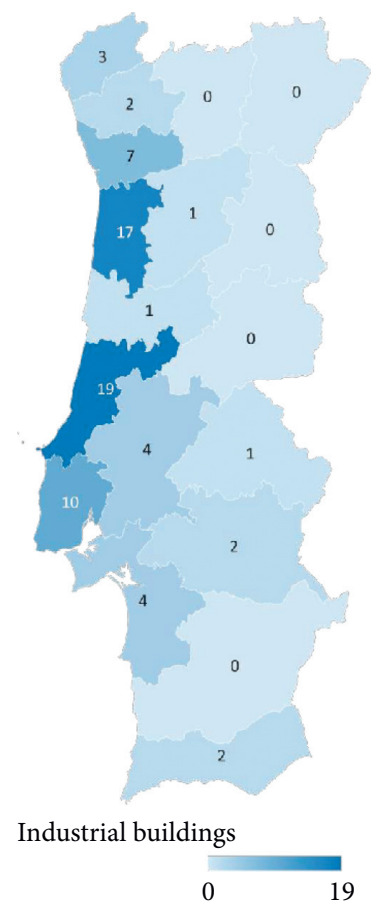

(a)

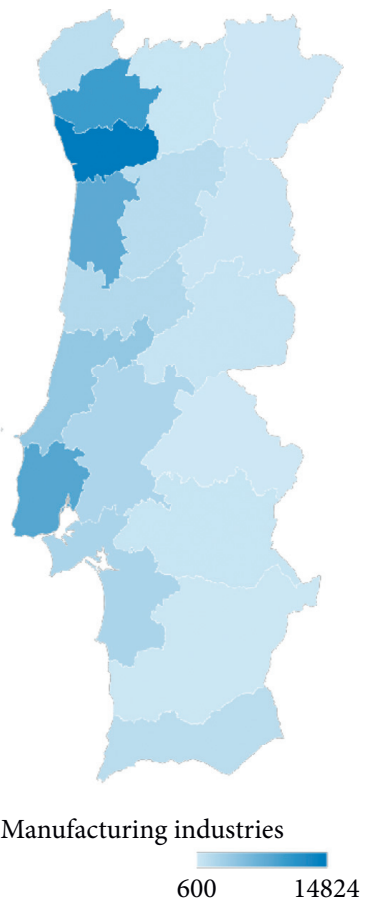

(b)

Figure 6: Location of industrial buildings in Portugal: (a) collected projects and (b) manufacturing industries in 2017. 


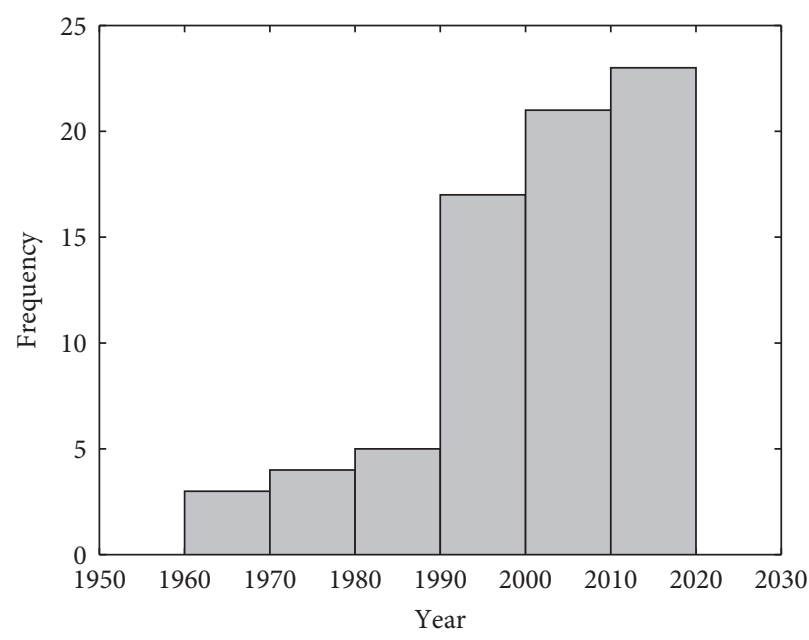

(a)

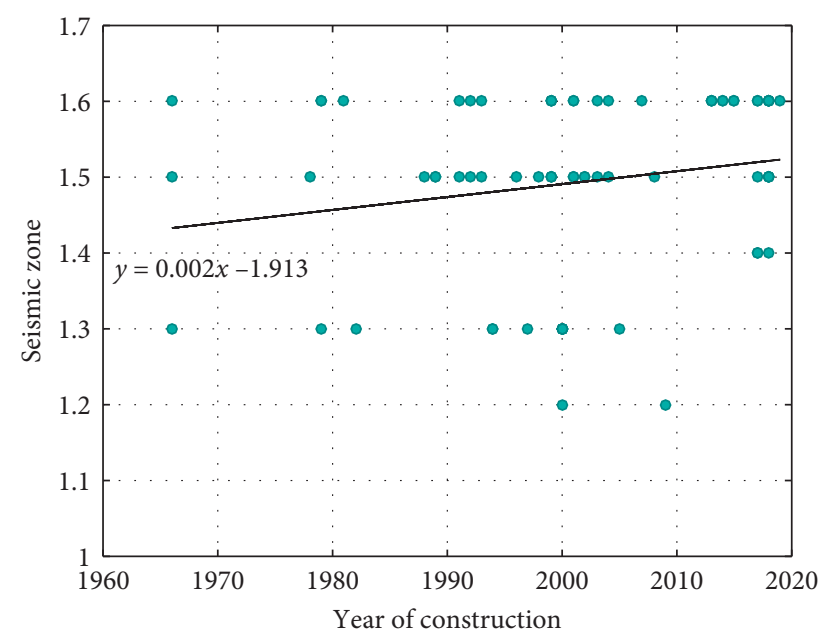

(b)

Figure 7: (a) Distribution of number of buildings analysed by the year of the project. (b) Evolution of the seismic zone with the year of the project.

of newer structures in the higher seismic zones (lower seismic hazard).

In addition to the location and period of construction, the characterisation of the RC precast buildings involved the collection of several structural parameters regarding the global geometry, material properties, columns section details, and beam-to-column connections, as described in Table 1. The data, and corresponding statistics, associated with each property are presented in the following sections, together with additional, indirect, structural parameters that could provide important indications on the design principles adopted for different periods or regions.

In the following sections, the evolution of the properties defined in Table 1 is evaluated considering a total of 73 buildings. However, it should be mentioned that in some design projects it was not possible to identify all properties, namely, the type of claddings and the beam-to-column connections.

3.2. Global Geometry. The first geometric property addressed regards the identification of the main typologies of precast $\mathrm{RC}$ buildings. Based on the survey carried out, it was possible to identify 4 main typologies that are illustrated and described in Figure 8 and Table 2, respectively.

The most traditional configuration consists of prestressed beams, with up to $45 \mathrm{~m}$ spans, simply supported on precast columns fixed at the base [5]. Yet, this configuration may present deviations regarding the properties of the longitudinal beams, which can have variable (T1), constant (T2), or truss (T3) configuration, or at the column properties which can feature a "Y" shape at the region of the connection with the longitudinal beams (T4).

Based on the collected data, it is apparent that the majority of the buildings in Portugal correspond to the Typology $1(86 \%)$ and Typology $3(11 \%)$, while only $2 \%$ of the cases are associated with Typology 2 and Typology 4 (Figure 9).
TABLE 1: List of properties collected for each RC precast building.

Global geometry

Typology

Number of storeys

Area upper storeys

Building height

Number of spans in longitudinal direction

Number of spans in transverse direction

Span length in longitudinal direction

Span length in transverse direction

Type of claddings

\begin{tabular}{l} 
Material properties \\
Concrete compressive strength \\
Reinforcement yield strength \\
\hline Column section details \\
Width \\
Length \\
Longitudinal reinforcement \\
Transverse reinforcement \\
\hline Beam-to-column connection \\
Number of dowels \\
Dowel diameter \\
Corbel span \\
\hline
\end{tabular}

As regards the number of storeys, it is apparent that the majority of the precast buildings are single-storey buildings (Figure 10(a)) with a total height that is below $10 \mathrm{~m}$ for the majority of the cases (Figure 10(b)).

The values of building height are in line with the study conducted in [1] for the general industrial facilities in Portugal, whose results are illustrated in Figure 5. Regarding the number of storeys, it is important to note that, except in one case, the upper storeys are only representative of a fraction of the total area of the building (Figure 11).

In terms of plan geometry, the properties vary significantly depending on the building direction analysed. In the direction along the longer beams (assumed as longitudinal hereinafter), the number of spans is generally low (1 or 2), 


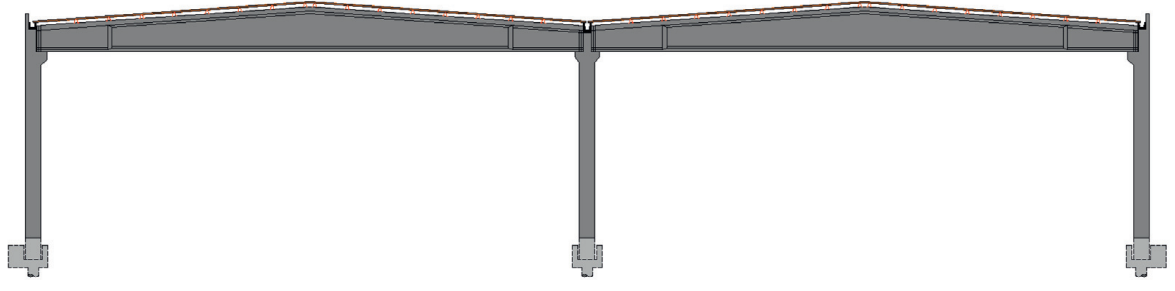

$\mathrm{T} 1$

(a)

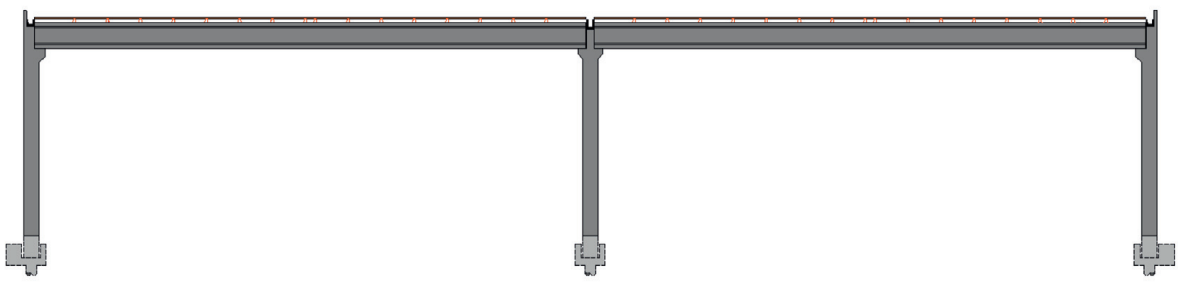

$\mathrm{T} 2$

(b)

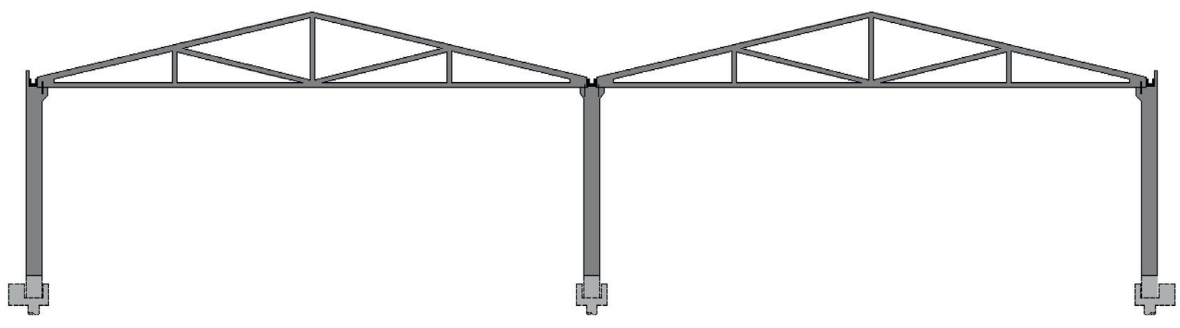

T3

(c)

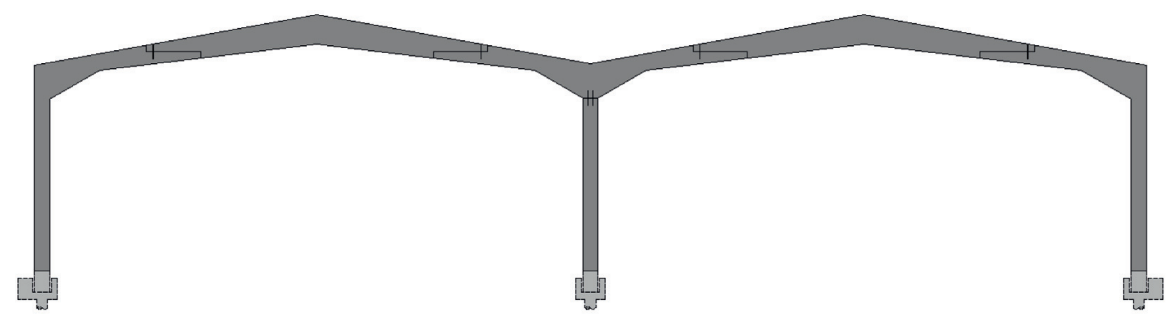

$\mathrm{T} 4$

(d)

FIGURE 8: Description of the main RC precast typologies identified in Portugal: (a) variable cross-section I shaped prestressed beams; (b) constant cross-section prestressed beams; (c) truss beams; (d) beam with Y shape at the connection.

TABLe 2: Precast industrial buildings typologies identified.

\begin{tabular}{lcccc}
\hline Type & Structural typology & Columns & Beams & Connections \\
\hline T1 & One-storey parallel portals & Fixed at the base & $\begin{array}{c}\text { Variable cross-section I shaped } \\
\text { prestressed beams }\end{array}$ & $\begin{array}{c}\text { Pinned/friction beam-to-column } \\
\text { connection }\end{array}$ \\
\hline T2 & One-storey parallel portals & Fixed at the base & $\begin{array}{c}\text { Constant cross-section } \\
\text { prestressed beams }\end{array}$ & $\begin{array}{c}\text { Pinned/friction beam-to-column } \\
\text { connection }\end{array}$ \\
\hline T3 & One-storey parallel portals & Fixed at the base & Truss beams & $\begin{array}{c}\text { Pinned beam-to-column } \\
\text { connection }\end{array}$ \\
\hline T4 & One-storey parallel portals & Fixed at the base & $\begin{array}{c}\text { Beam with Y shape at the } \\
\text { connection }\end{array}$ & $\begin{array}{c}\text { Pinned beam-to-column } \\
\text { connection }\end{array}$ \\
\hline
\end{tabular}




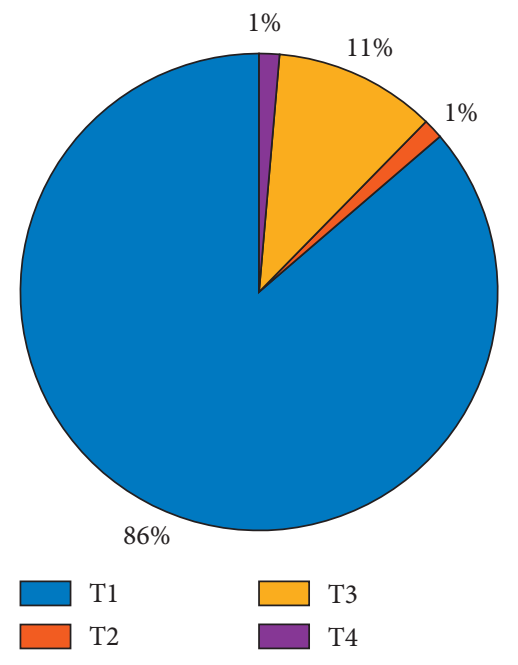

FIgURE 9: Percentage of precast RC buildings with different typologies.

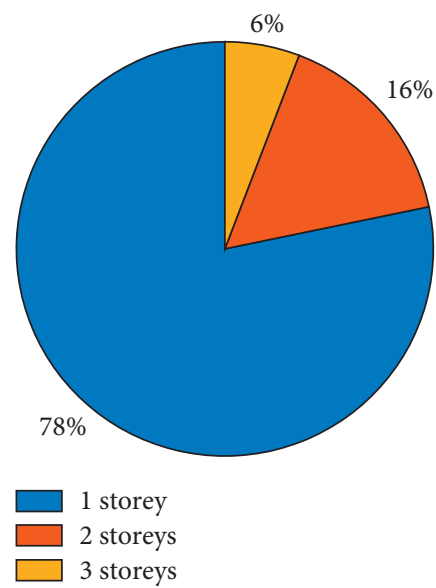

(a)

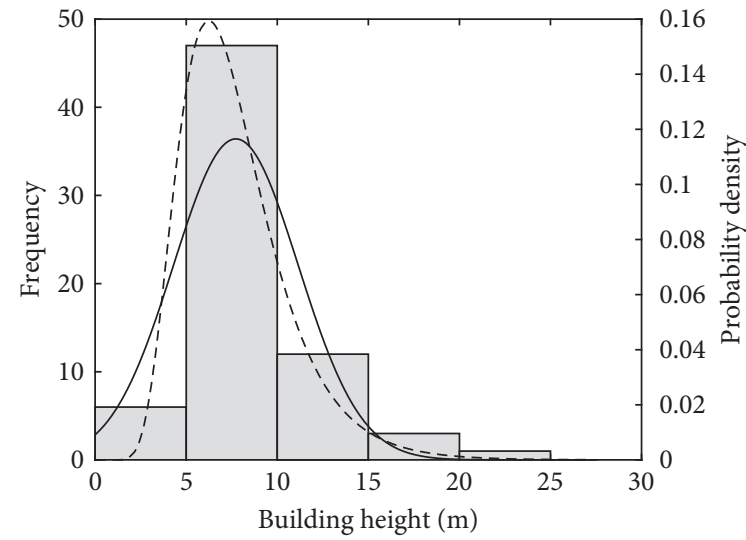

Histogram

Normal dist. (@²: not sat.)

- - - Log-normal dist. (@2 $1 \%$ sat.)

(b)

FIgURE 10: (a) Number of storeys. (b) Histogram and probability distributions associated with the number of storeys and building height.

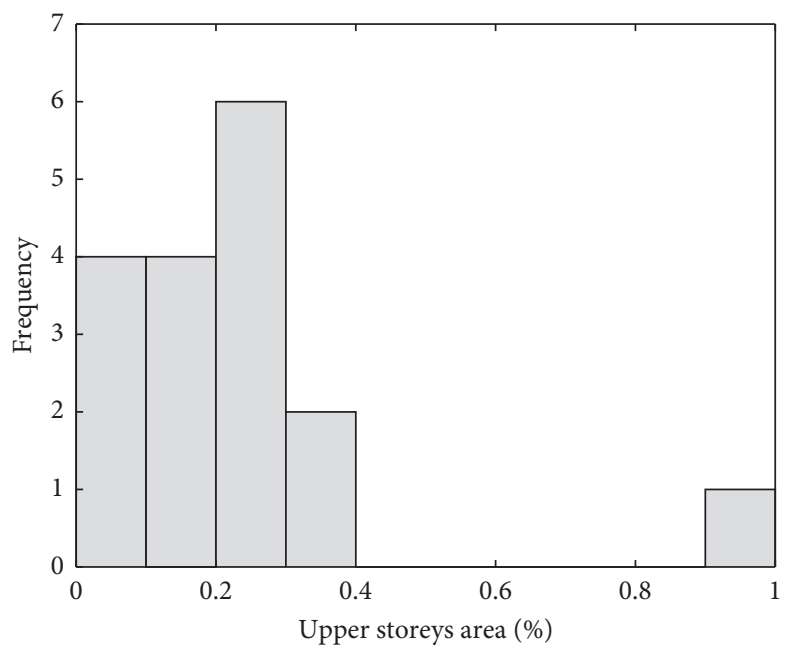

Figure 11: Ratio of upper storeys area with respect to the ground storey. 
and the beams length can reach values up to $50 \mathrm{~m}$ (Figure 12). In addition, when analysed with respect to the construction period, the spans length seems to increase with the year of construction, which is probability related with improvements on the manufacturing and construction processes (Figure 13).

On the other hand, in the transverse direction, the number of spans is typically higher and features smaller lengths, up to $15 \mathrm{~m}$ (Figure 14).

Finally, based on the data collected, three main types of cladding systems were identified: infill masonry and horizontal and vertical RC precast panels. Among these, the use of horizontal panels seems to be most common, being observed in $50 \%$ of the buildings, while infill masonry and vertical panels were identified in $33 \%$ and $17 \%$ of the cases, respectively. The increase in the use of vertical cladding panels in the last decades (Figure 15) indicates that this solution appears to become more appealing, as a consequence of improved precast construction processes as well as transport and installation methods. On the other hand, it is still somehow surprising that infill masonry represents an important percentage of the buildings in the last decade and about one-third of the total number of buildings.

3.3. Material Properties. The material properties presented in the following plots refer to the classes indicated in the design projects and, therefore, do not necessarily correspond to the actual values found in the existing buildings.

Regarding the concrete class, Figure 16 shows a large dispersion of the concrete compressive strength (corresponding to the cylinder test) considered in the design process, despite the apparent larger employment of concrete strengths between $20 \mathrm{MPa}$ and $30 \mathrm{MPa}$. Notwithstanding the great variability, when examined with respect to the year of construction, it seems clear that the concrete classes increase with the period of construction.

Regarding the reinforcement, the number of classes is much lower than the ones found for concrete, and it is apparent that most of the RC members were built with A400 and A500 steel grade (Figure 17(a)). As for the reinforcing steel, it is possible to observe an evolution of the steel grade with the year of construction (Figure 17(b)).

3.4. Column Properties. In this section, the properties of the columns, namely, the section dimensions and reinforcement ratios, are described. The emphasis given to the properties of the vertical elements stems from their relative importance in the seismic behaviour of these structures, with respect to the beam members that, by virtue of their properties and structural arrangement, are expected to remain essentially undamaged. In terms of columns cross-section, Figure 18 shows the frequency and associated normal and log-normal distributions of the columns width and length (defined as the dimension along the longitudinal direction).

The analysis of the results revealed that in only about one-third of the cases the columns are square. At the same time, the collected data indicated that, for the majority of the rectangular columns, the length-to-width ratio remains below 2 (Figure 19(a)).

Another relevant geometric parameter regards the height-to-length ratio, as it provided an indication on the target aspect ratios generally considered in these buildings. Figure 19(b) indicates that, for the analysed cases, this ratio varies essentially between 12 and 25 , corresponding to large slenderness and, is therefore indicative that these columns are more prone to develop flexural type of failures, at least in cases where the cladding system is continuous along the height of the column.

In order to assess a possible reason for the variability observed in the relation between the height and length of the columns, this ratio, was plotted against the year of the project and the seismic zone associated with the building location (Figure 20). Considering the above considerations, it would be expected that the ratio could decrease (indicative of less slender columns) with the increase of the level of seismic loads, being assessed in terms of seismic regulation (year of project) or seismic intensity (seismic zone). Nonetheless, the results presented in Figure 20 indicate that the ratio is essentially independent of the year of construction and, contrary to what would be expected, it appears to increase with the increase in the seismic loads. It is noted that, in the Portuguese seismic zonation, the seismic intensity decreases with the increase in the seismic zone. These conclusions seem to indicate that the seismic combination of loads was not the conditioning action or that, at the time of design, no seismic regulation was available. The latter, however, seems less plausible given that most of the collected data refers to buildings designed after 1990 (see Figure 7) and, therefore, after the introduction of the first reference seismic regulation, the Regulamento de Segurança e Ações para Estruturas de Edifícios e Pontes [6]. Furthermore, the increase in buildings height over time (for higher versatility and to satisfy different industry requirements) was certainly somehow compensated with the optimization of the structural design, construction processes, and the use of higher quality materials, allowing reduction of the elements cross-section requirements.

Finally, the properties of the columns are evaluated in terms of longitudinal and transverse reinforcement ratios (see Figure 21). The results indicate that the mean value of the longitudinal reinforcement ratio is approximately $1.5 \%$, while for the transverse case, the average value approaches $0.3 \%$. These values are somehow higher that the ones observed in conventional RC structures without seismic design that, according to Furtado, Costa, Arêde, and Rodrigues [7] and Sousa, Costa, Costa, Romão, and Candeias [8], are about $50 \%$ of the ones measured in the precast buildings. This low level of transverse reinforcement results from the fact that, up to 2019, the concrete design codes (REBA [9] and REBAP [10]) define the spacing of the stirrups based on the diameter of the longitudinal bars and size of the elements and never related with the seismic zone.

As for the height-to-column ratio, it is also difficult to find a trend between the reinforcement ratios and the year or seismic zone where the buildings are located. Nonetheless, it is apparent there is a slight increase in both ratios with the 


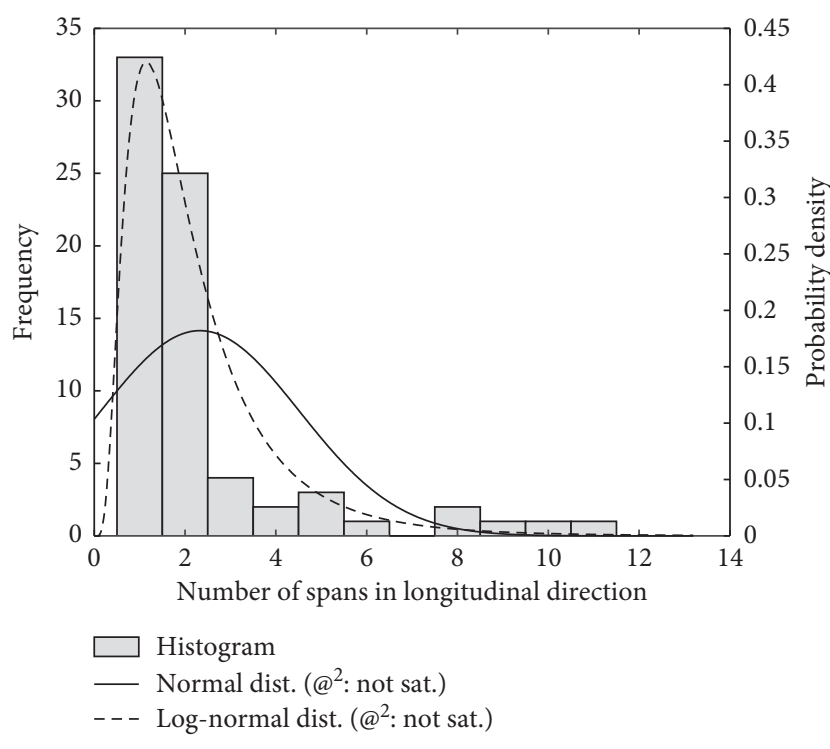

(a)

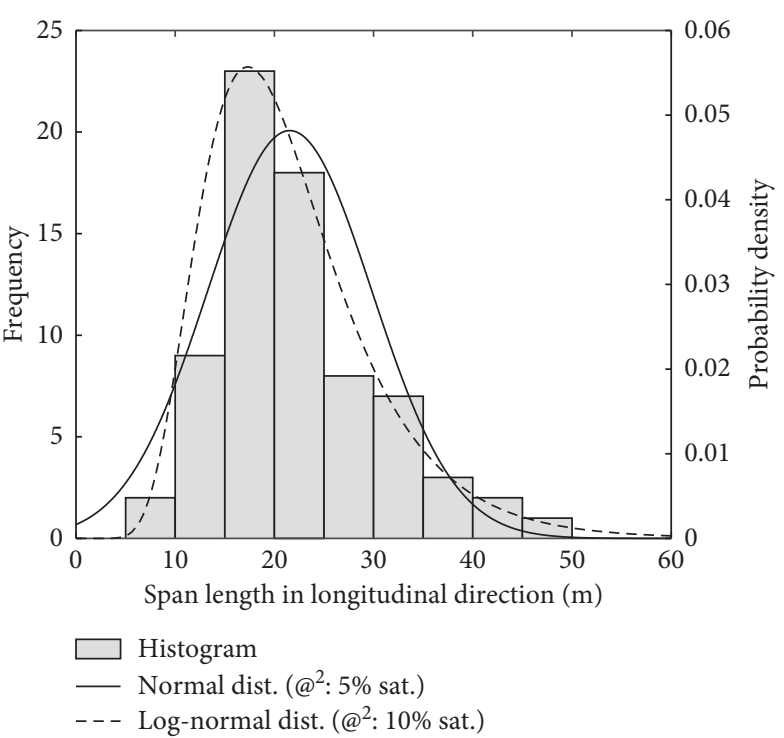

(b)

FIGURE 12: Histogram and probability distributions associated with the (a) number and (b) length of the spans (in the longitudinal direction).

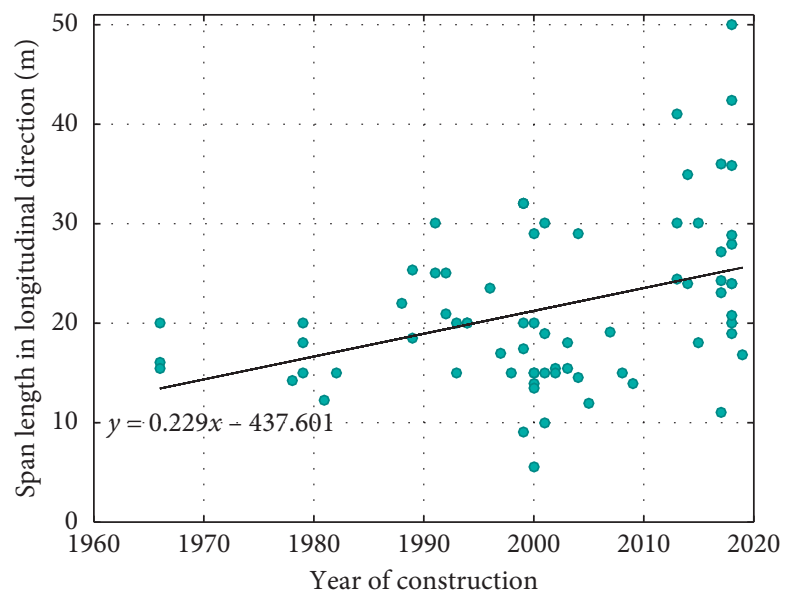

FIgURE 13: Evolution of span length in the longitudinal direction with the year of construction.

year of the project (see Figure 22). The apparent increase in both ratios with the seismic zones is somehow justified by the fact that the buildings collected in higher seismic zones (lower seismic hazard) have been built later and, therefore, reflect the tendency for an increase in reinforcement ratios with the year of construction (see Figure $7(b)$ ).

3.5. Beam-to-Column Connection. Past earthquakes showed that beam-to-column connections represent one of the main sources of damage in precast structures [11-14]. The adequate characterisation of these elements is therefore critical to study the structural behaviour of these structures.

In addition to the friction force developed at the surface between the beam and the columns corbel, the lateral strength of these systems depends on the number and size of connecting dowels. Among the analysed design projects, in nearly $60 \%$ of the cases, it was possible to access the details about the dowel connection. In the remaining cases, however, no reference to these elements was found, which may indicate that, in a reasonable amount of buildings, the beamto-column connections could be ensured simply by friction. Considering the limited information often available in older projects, it is also possible that in some cases a standard dowel connection could be assumed during the construction phase, without specifying the details in the design project.

Regarding the cases in which the dowels were detailed, the variability is significant in terms of both the number and diameter of the dowels (Figure 23). It is, thus, not surprising that the total dowel area found in each beam-to-column connection follows a distribution that is essentially uniform (Figure 24(a)).

Looking for a reliable relation between the dowel properties with structural or nonstructural parameters, it 


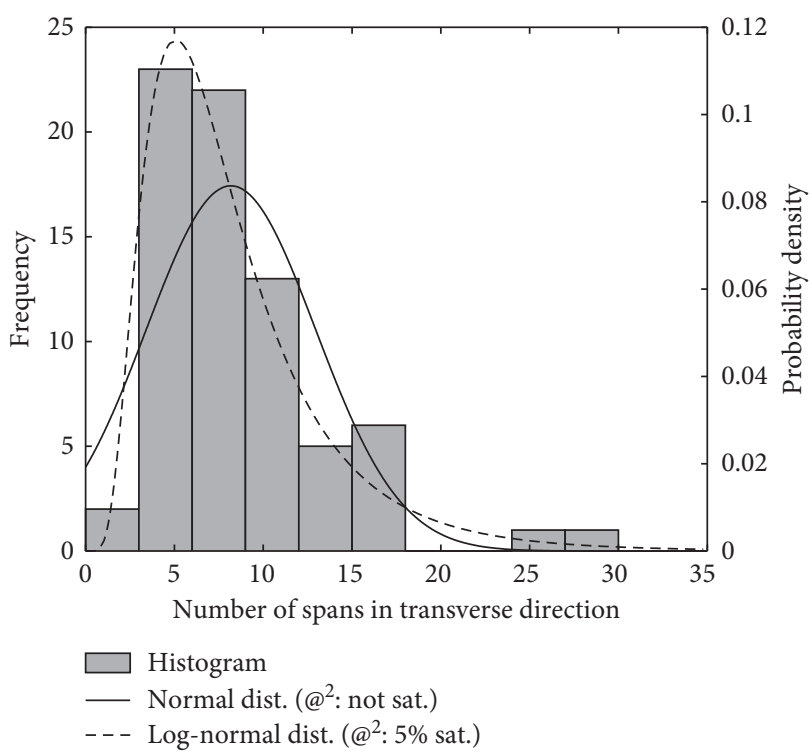

(a)

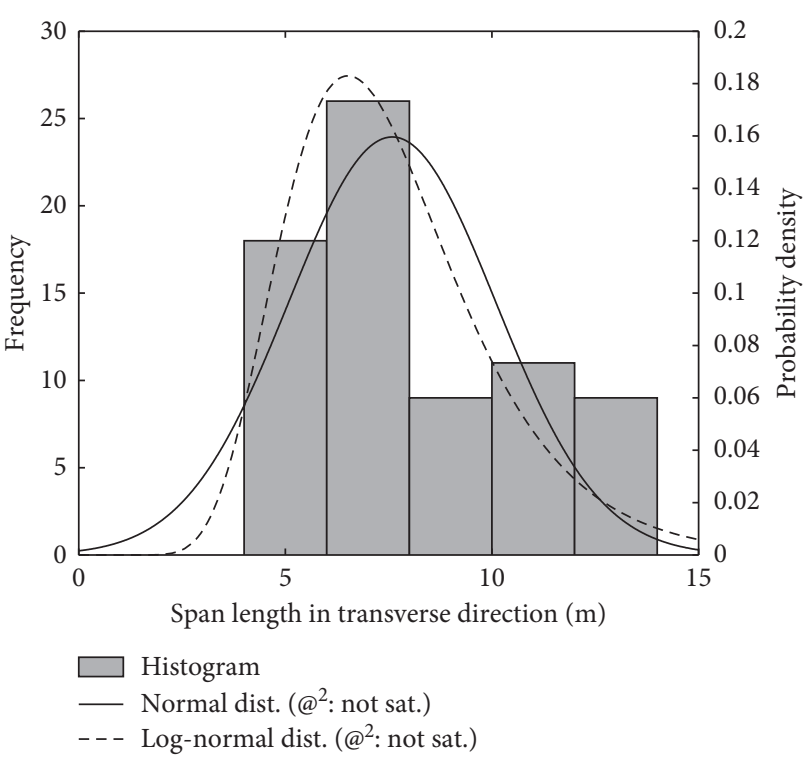

(b)

FIGURE 14: Histogram and probability distributions associated with the (a) number and (b) length of the spans (in the transverse direction).

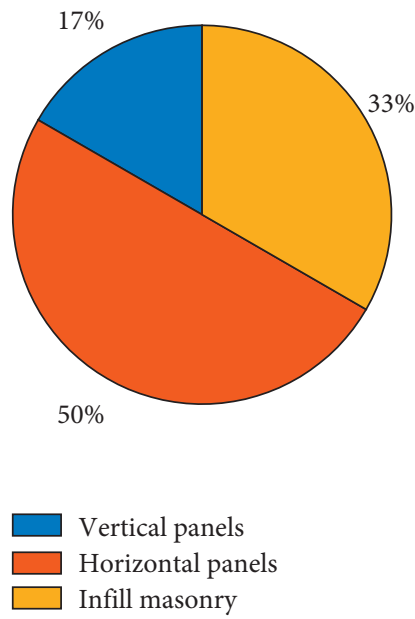

(a)

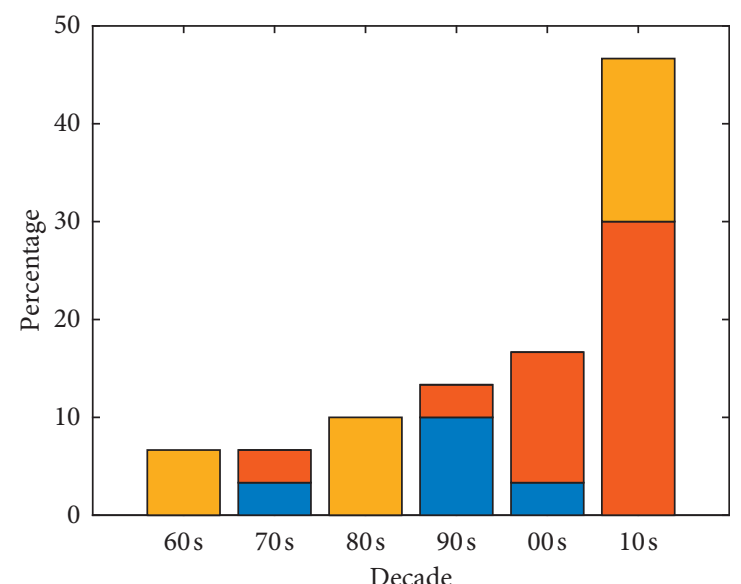

Vertical panels Horizontal panels Infill masonry

(b)

FiguRE 15: Variation of type of the cladding system by decade.

was found that the area of the dowels appears to be correlated with the beam span, notwithstanding the large dispersion observed (Figure 24(b)).

Regarding the evolution of the dowel properties with the year of construction, the results presented in Figure 25(a)) show that, only in the recent projects (essentially after 2000), the dowel connections are described in detail. As noted before, these results regard the description found in the design projects, which does not necessarily mean that no dowels were considered in the construction phase.

On the other hand, it is apparent that the dowels properties are not dictated by seismic provisions, since the area of dowels is not proportional to the design seismic action (Figure 25(b)); it is recalled that the seismic loads decrease with the increase in the seismic zone number.

Regarding the corbel properties, the results obtained from the data collected reveal values that vary between 10 and $50 \mathrm{~cm}$ (Figure 26). This figure also shows that, contrary to the dowel area, the corbel span seems to be independent of the longitudinal beam span.

3.6. Summary and Statistical Indicators. This section presents an overview of the data collected from 73 precast RC buildings, summarized in Table 3, highlighting the main 


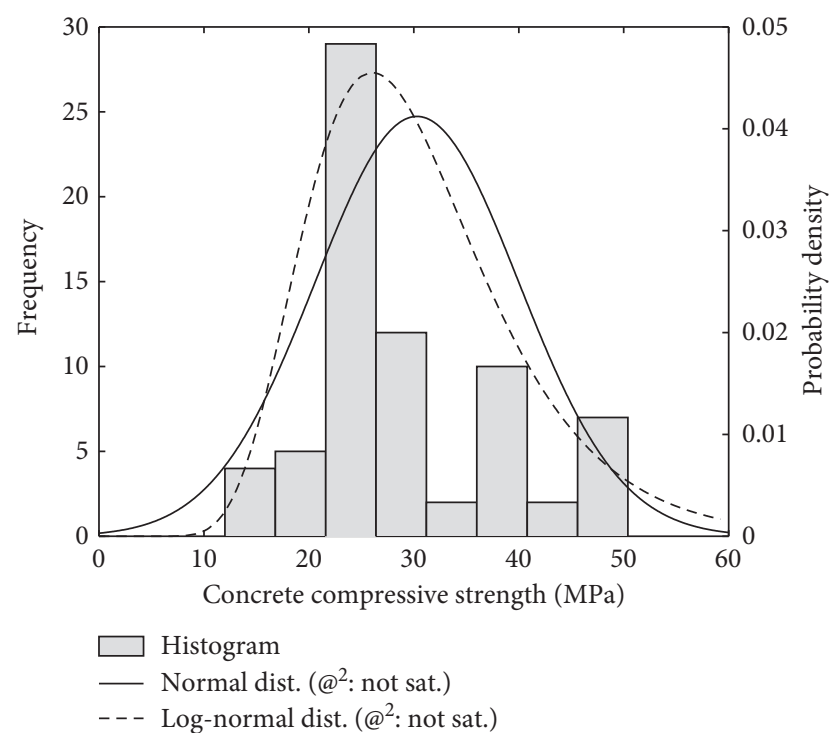

(a)

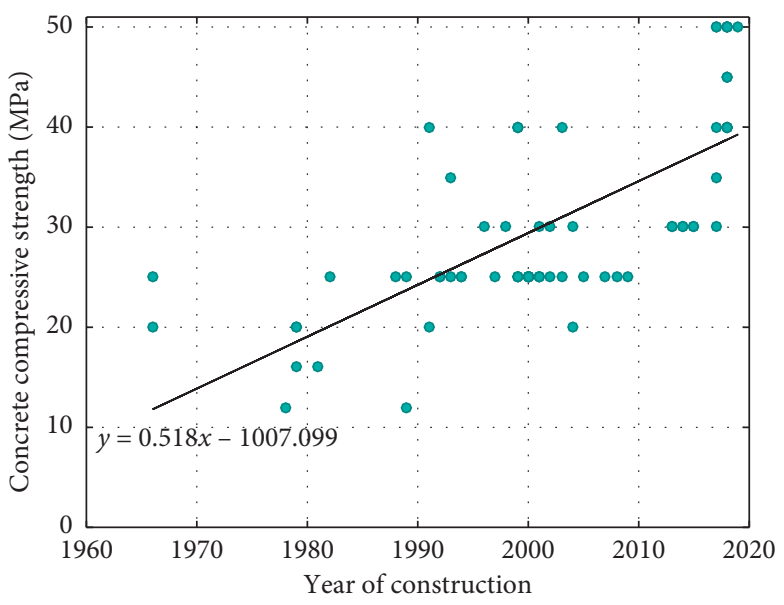

(b)

FIGURE 16: Concrete compressive strength: (a) histogram and probability distributions associated with the concrete compressive strength and (b) evolution with period of construction.

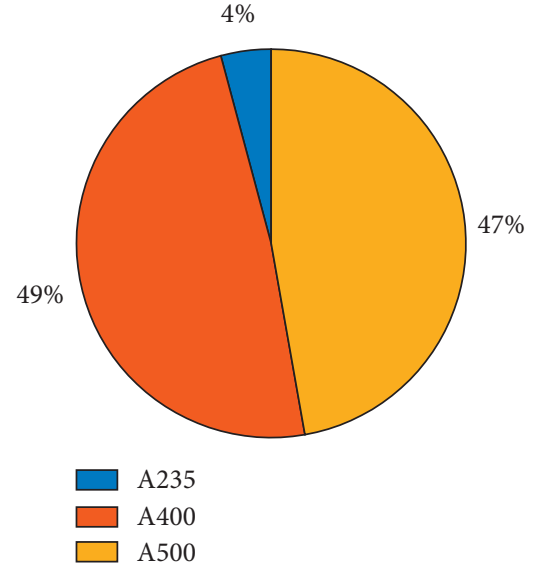

(a)

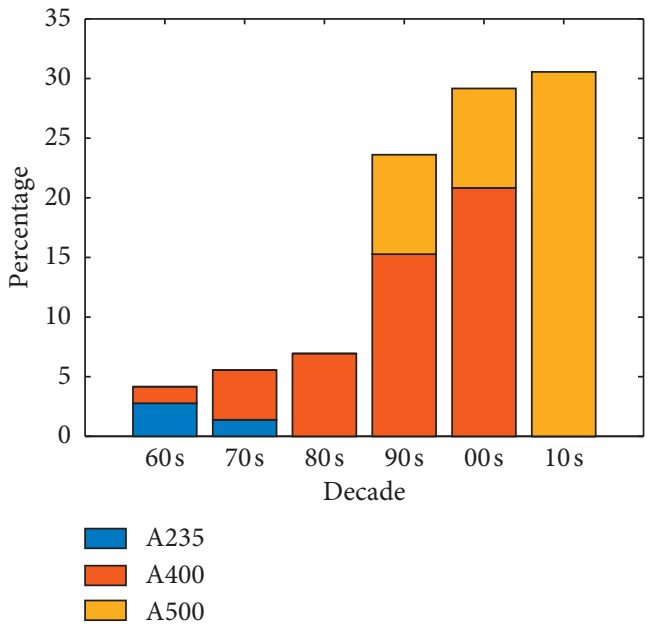

(b)

Figure 17: (a) Percentage and (b) distribution of reinforcement grade by year of construction.

findings together with the statistics derived for some of the properties.

Regarding the representativeness of the actual building stock, it was showed that the geographical location of the buildings analysed follows closely the actual distribution of industrial buildings. From a temporal point of view, most of the information collected refers to building built after 1990 and, therefore, after the introduction of the seismic regulation [6]. In theory, this could introduce a bias in the information gathered. When looking to the Italian example, around $20 \%$ of the precast buildings were constructed before 1980 and around $60 \%$ before 1996, without seismic concerns [15]. However, considering that in Portugal the prefabrication industry started to gain a relevant scale in the construction of industrial facilities especially during the 80s and 90s-the National Association of Prefabricated Concrete Industry (ANIPB) was founded in 1975-the asymmetry in the year of the project of the buildings (Figure 7) is certainly a reflection of the evolution of the prefabricated construction and, by that, the bias is not so significant. Moreover, the regressions carried out appear to indicate that the structural properties are independent of the seismic zone and, hence, the design seismic action. 


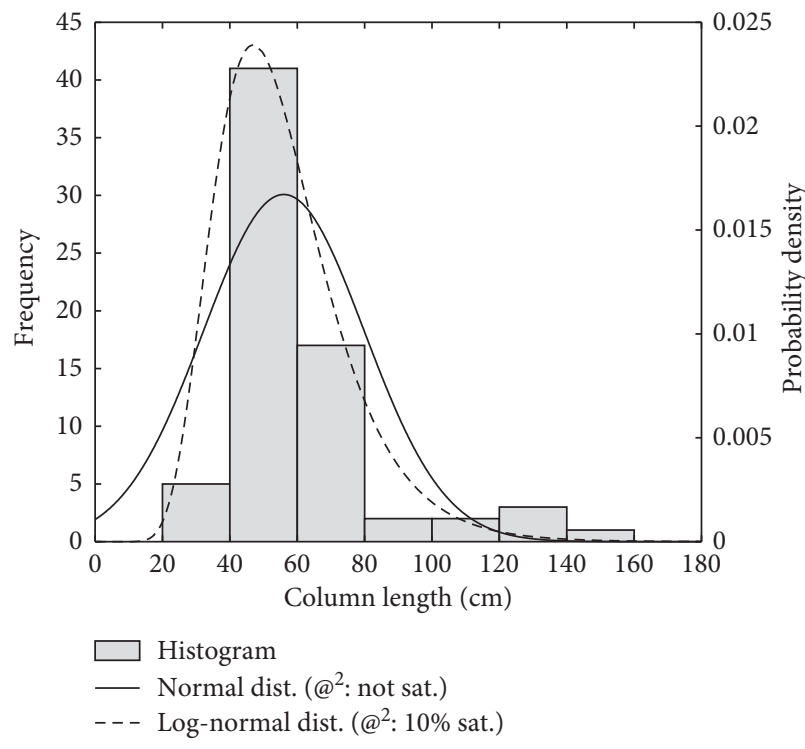

(a)

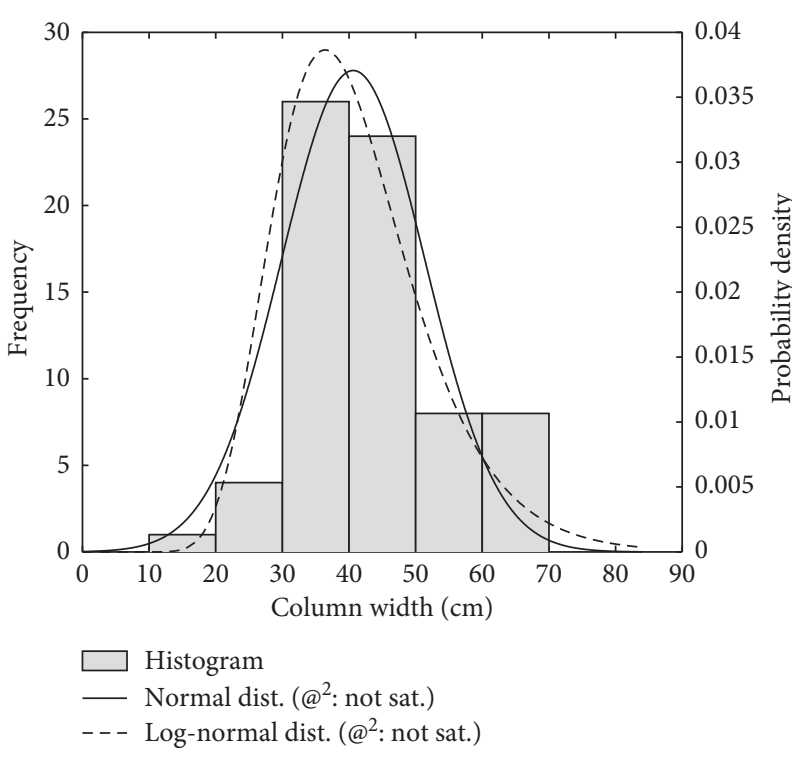

(b)

FIGURE 18: Histogram and probability distributions associated with the columns: (a) length and (b) width.

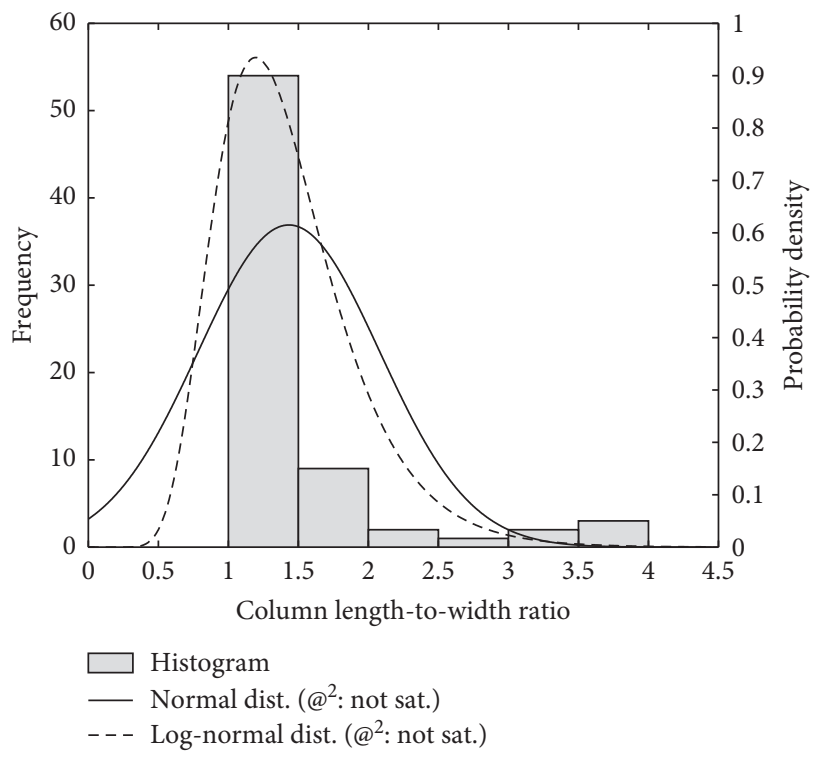

(a)

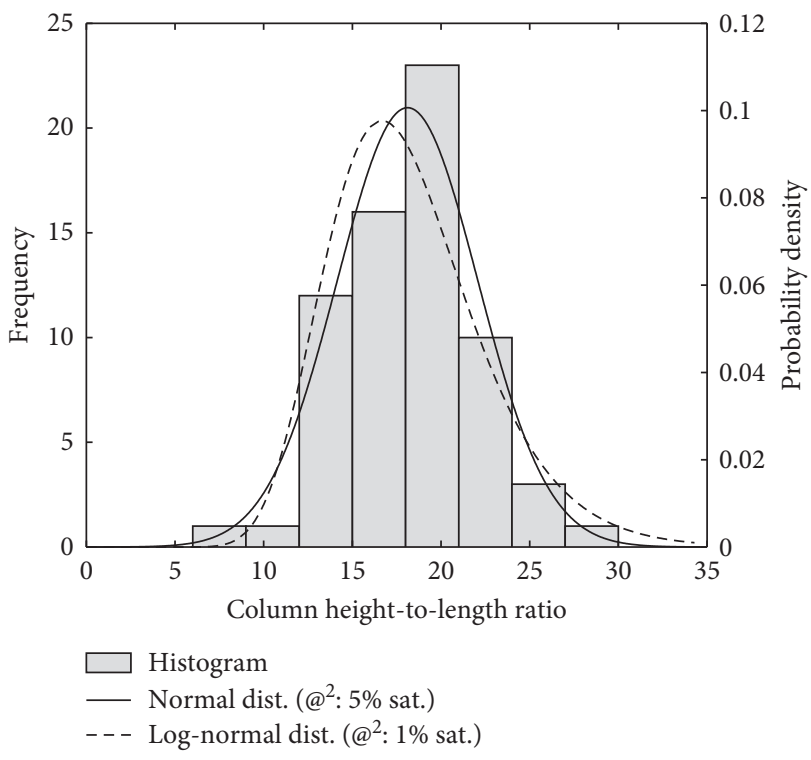

(b)

FIGURE 19: Histogram and probability distributions associated with the columns: (a) length-to-width ratio and (b) height-to-length.

\section{Comparison of Portuguese Database with Other European Countries}

In this section, the properties identified in the Portuguese building stock are compared with similar data collected in Italy and Turkey. Considering the damage observed in precast structures after recent earthquakes in these countries, the comparison of the properties of the collected buildings in view of the properties found in the other countries can provide indications of the expected behaviour of these structures if subjected to an earthquake in Portugal.
The comparisons made are naturally conditioned by the properties analysed in different studies. Yet, it was possible to establish comparisons regarding the structural typology, main dimensions, and columns properties, including longitudinal and transverse reinforcement ratios.

Regarding the data corresponding to Italy, it comprises the contribution of 3 different studies, namely, one carried out in Emilia-Romagna and Toscana regions and one comprising information collected from different regions promoted by the consortium ReLUIS and the Department of Civil Protection in Italy, hereinafter referred to as DPC/ 


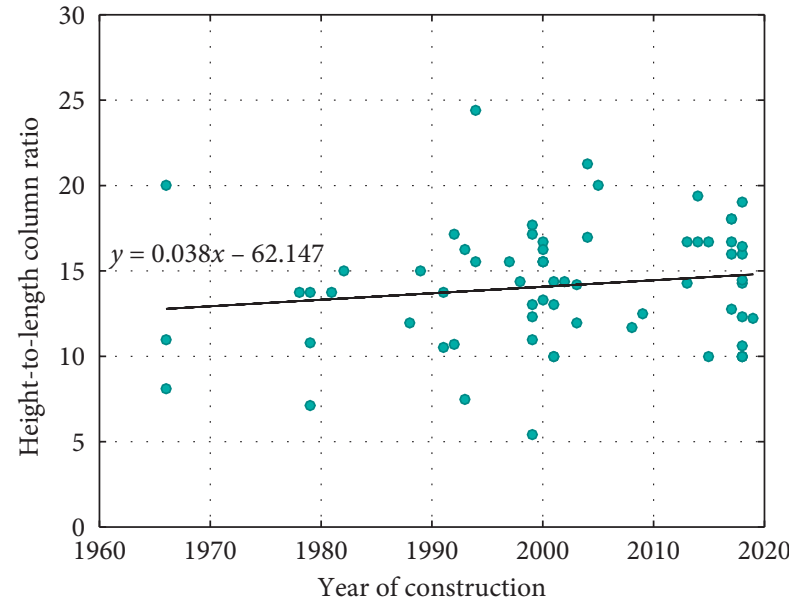

(a)

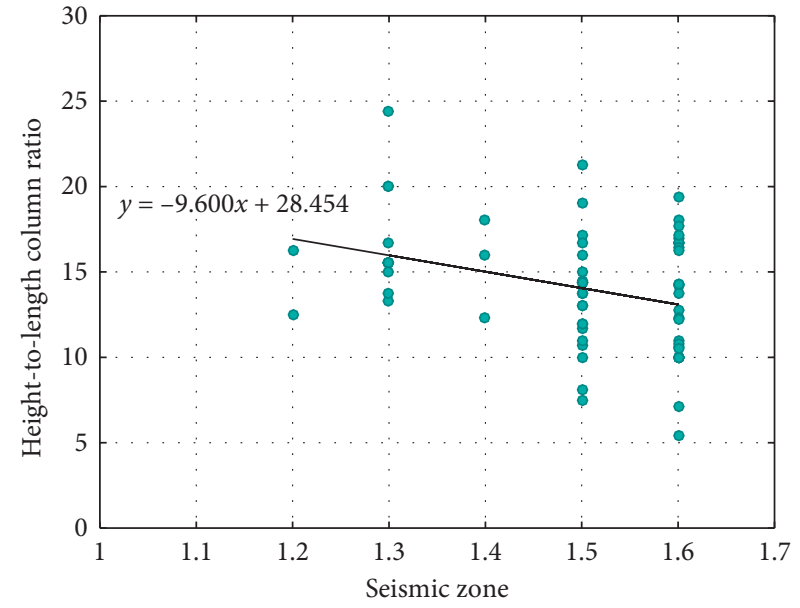

(b)

FIgURE 20: Evolution of height-to-column ratio with the (a) year of construction and (b) seismic zone.

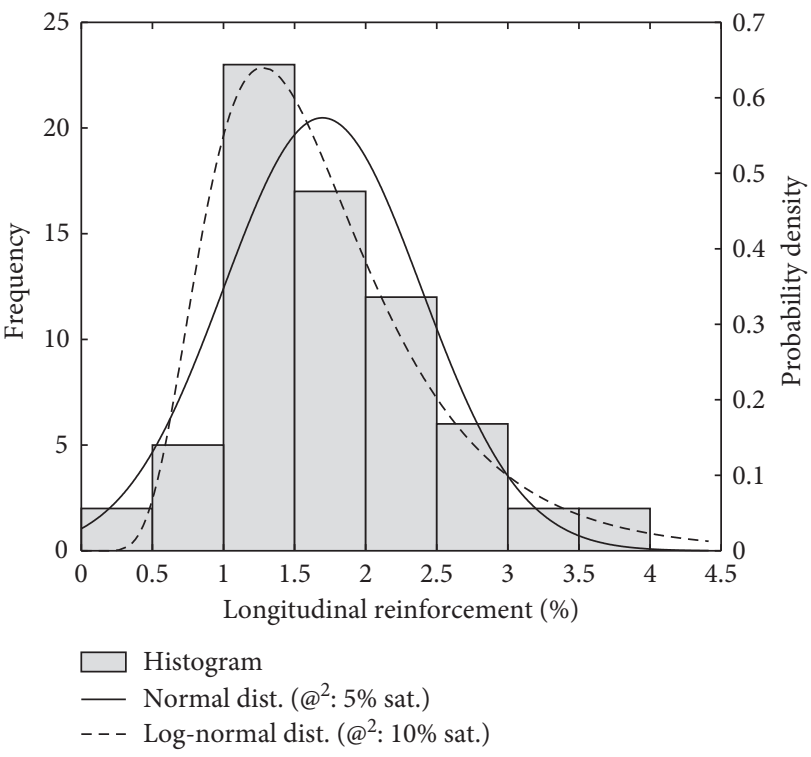

(a)

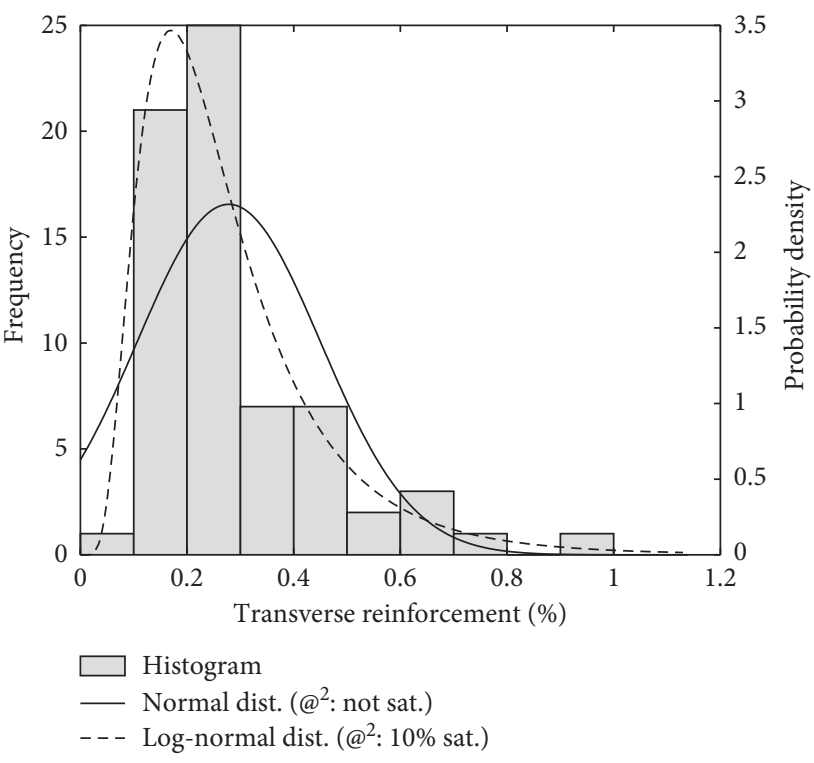

(b)

FIGURE 21: Histogram and probability distributions associated with the (a) columns longitudinal reinforcement ratio and (b) transverse reinforcement ratio.

ReLUIS. Additional information regarding the studies consulted can be found in the work carried out in [2] for Italy and by Senel and Kayhan (2010), for Turkey.

The first parameter addresses the date of construction of the buildings. This information may be relevant in the sense that the properties of the buildings can change as a function of code requirements, material properties, construction process, etc. The results presented in Figure 27 show that the buildings analysed in Portugal are more recent that the ones in Italy and Turkey. The organization of the data around the year 1998 is related with the information available in the Turkish database, which adopted this threshold associated with the implementation of a new code that establishes higher seismic loads [3].
Regarding the main building typology, according to Casotto, Silva, Crowley, Nascimbene, and Pinho [16] and [3], the most common typology found in Italy and Turkey is consistent with the one found in Portugal that essentially consists of 1-storey portal frames with beams simply supported on cantilever column fixed at the base. Regarding the beams cross-section, the results shown in Figure 28 indicate that those are also consistent, at least in regard to the Italian ones (data relative to this property was available only in the study carried out in Emilia-Romagna).

Regarding the beam span in the main direction, Figure 29 shows that the difference between the countries is not significant. In fact, the apparent larger values measured in the Portuguese buildings can be, at least, partially related to 


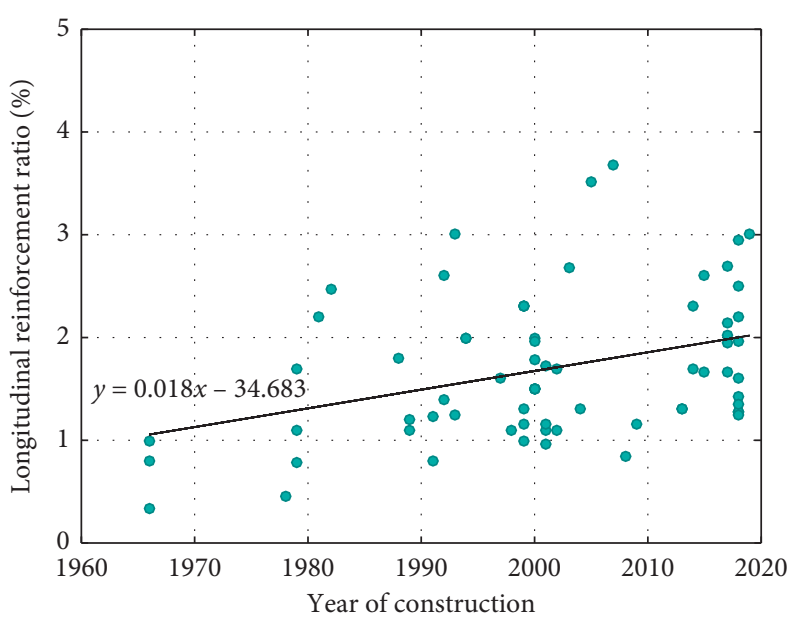

(a)

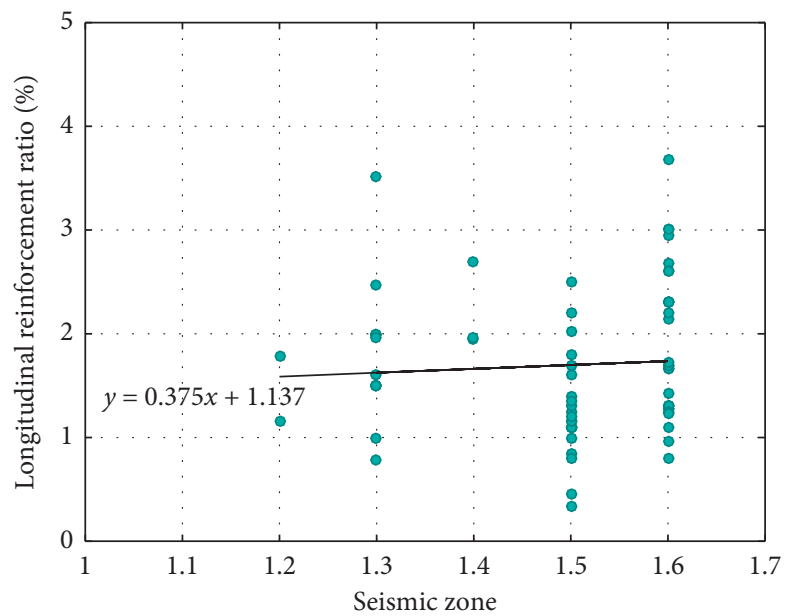

(c)

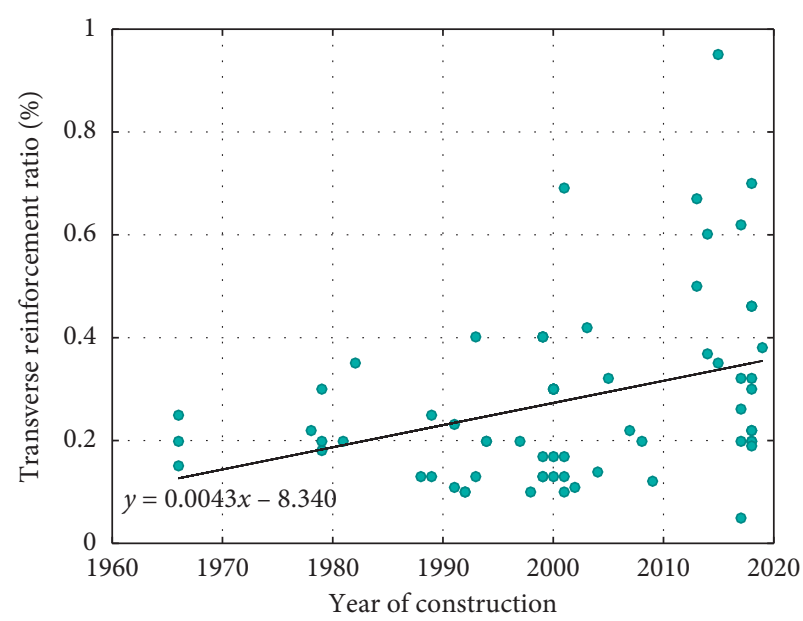

(b)

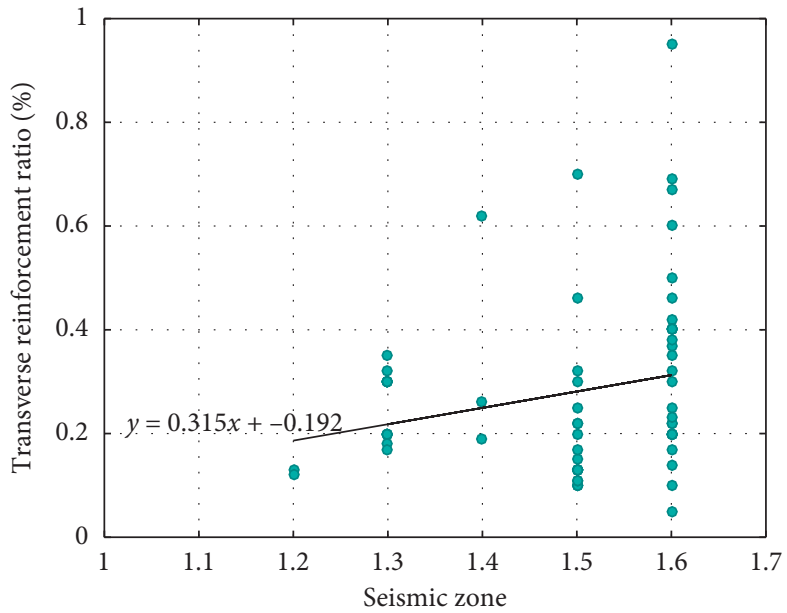

(d)

FIGURE 22: Evolution of (a) longitudinal reinforcement and (b) transverse reinforcement with the year of construction and evolution of (c) longitudinal reinforcement and (d) transverse reinforcement with the seismic zone.

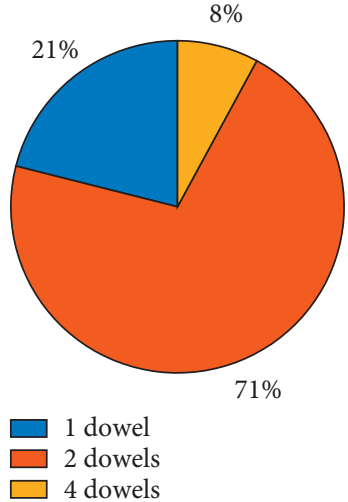

(a)
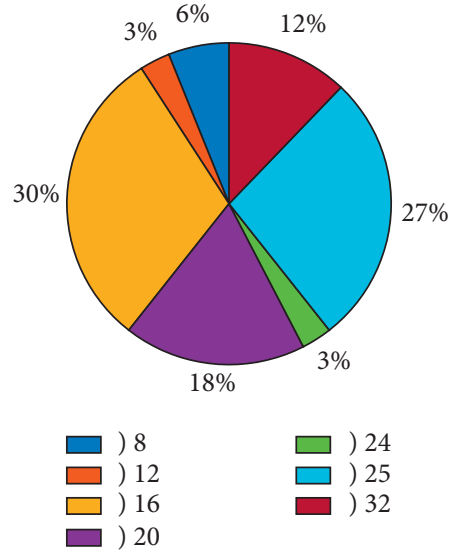

(b)

Figure 23: Dowels in beam-to-column connections (a) number and (b) diameter. 


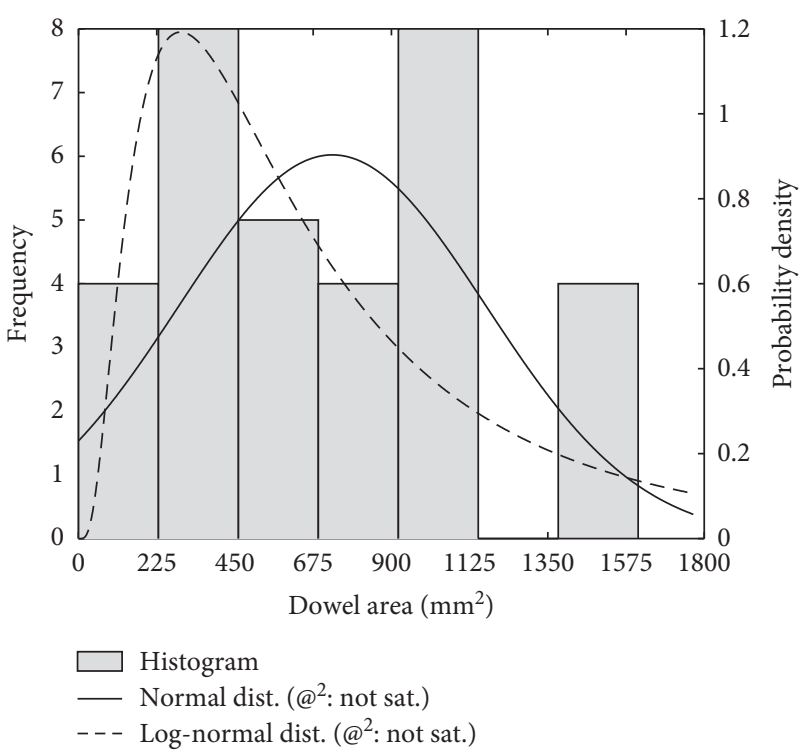

(a)

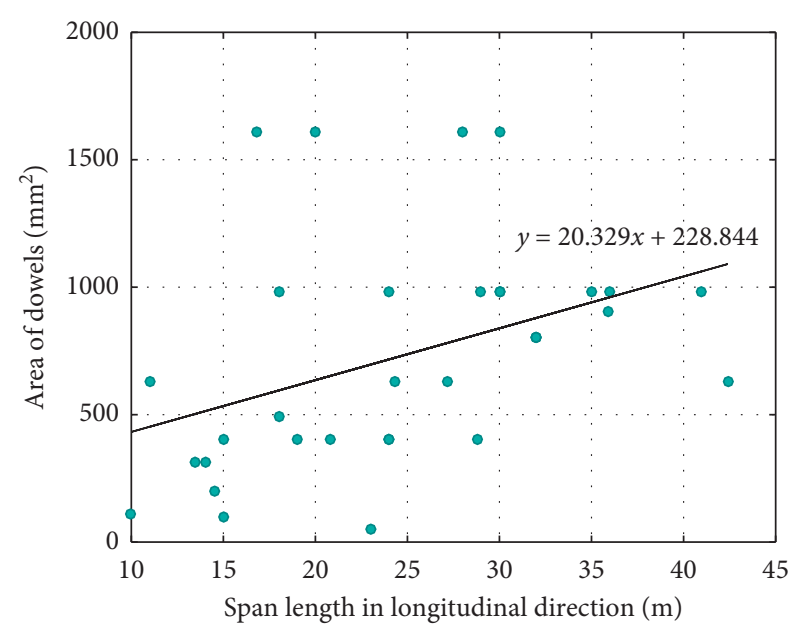

(b)

Figure 24: Dowels area: (a) histogram and probability distributions associated with the area of dowels and (b) evolution with the span length along the longitudinal direction.

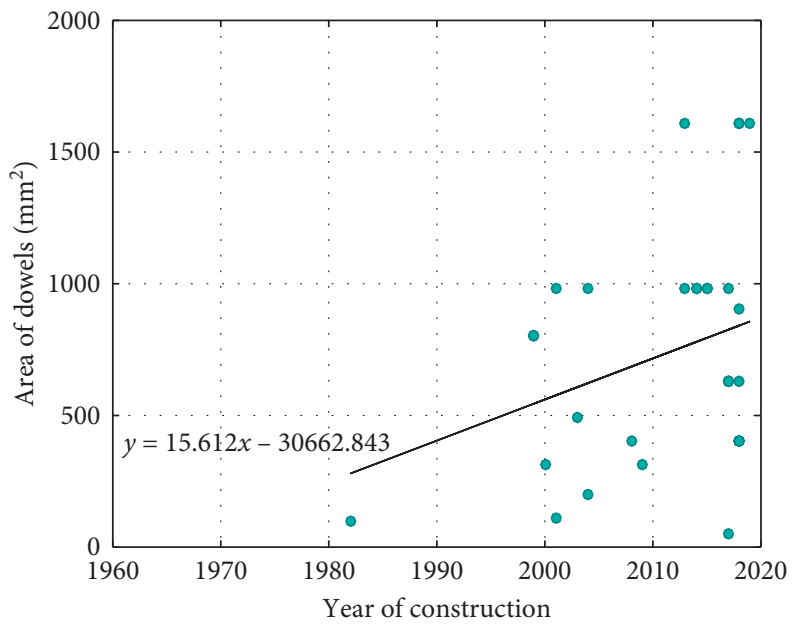

(a)

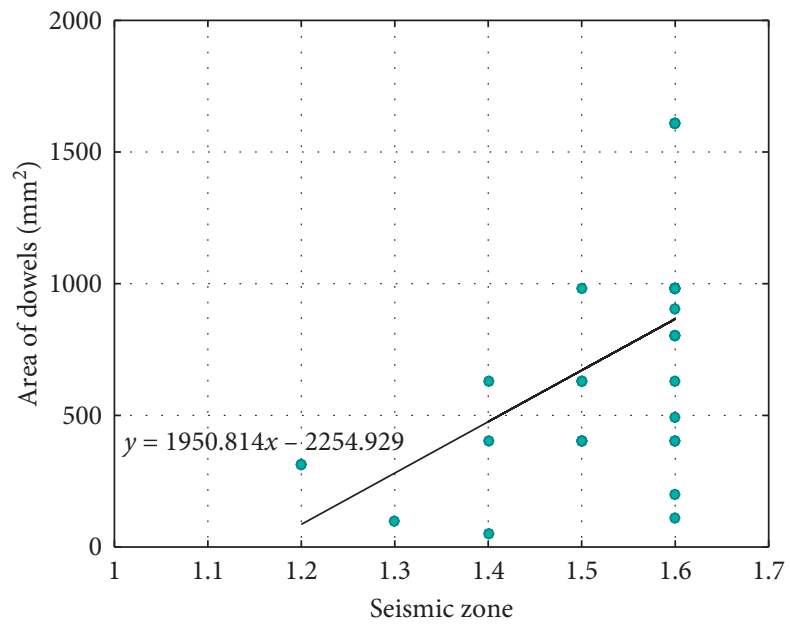

(b)

FIGURE 25: Evolution of dowels area in beam-to-column connections with the (a) year of construction and (b) seismic zone.

younger age of these buildings with respect to the other databases. As noted in Figure 13 and in [2], the beam spans in the main direction tend to increase with the year of construction.

As regards the columns properties, Figure 30 indicates that the columns height in Portugal appears to be higher than the ones measured in Turkey. On the other hand, the ratio between the height and the length of the columns, which is a measure of their slenderness, is in line with the data collected in Italy (Figure 31).

Finally, regarding the reinforcement ratios, different trends were observed whether related with the longitudinal or transverse reinforcement ratios. In regard to the longitudinal ratio, Figure 32 shows small differences between the Portuguese and Turkish buildings. In one side, values lower than $1 \%$ were observed only in Portugal; it is also apparent that a larger percentage of buildings feature large reinforcement ratios (e.g., higher than $2 \%$ ). On the other hand, based on the results present in Figure 33, it seems clear that the Portuguese buildings feature lower levels of transverse reinforcement, notwithstanding the significantly younger age of the buildings included in the Portuguese database with respect to the Turkish ones (see Figure 27). This lower ratio may anticipate lower ductility capacity (lower 


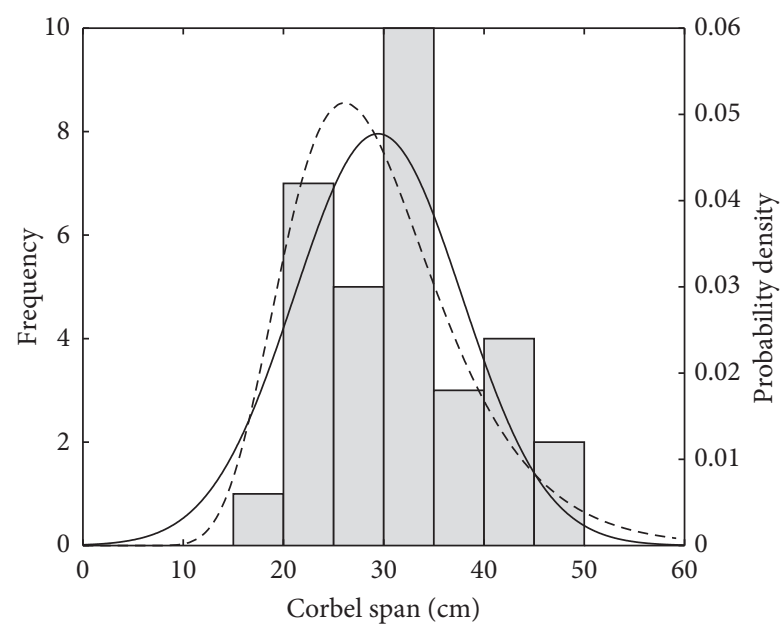

Corbel span $(\mathrm{cm})$

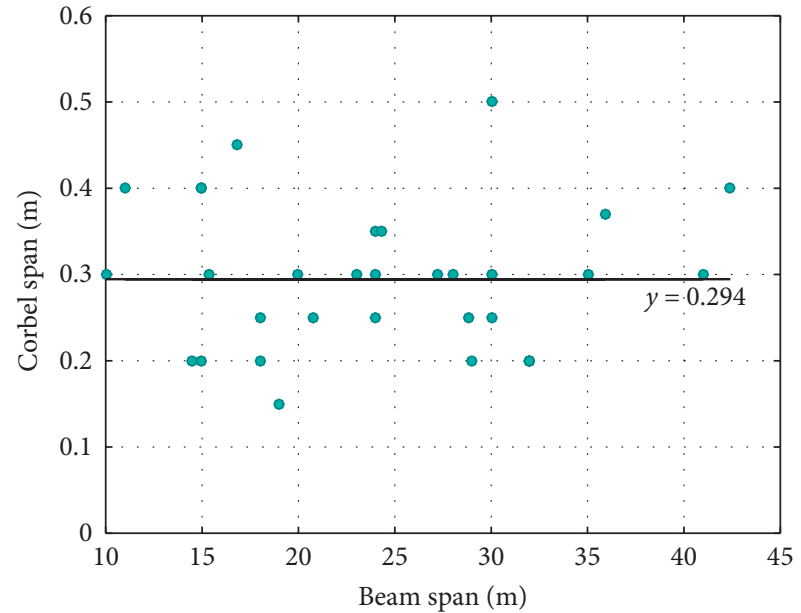

(b)

FIGURE 26: Corbel span in the beam-to-column connections. (a) Histogram probability distributions associated. (b) Corbel span with beam span relation.

TABLE 3: Summary of the distribution properties for the different parameters collected.

\begin{tabular}{|c|c|c|c|c|c|c|c|c|}
\hline Parameter & Mean & Median & Mode & $\operatorname{COV}(\%)$ & Min & Max & Distribution & $p$ value $(\%)$ \\
\hline Number of spans in longitudinal direction & 2.3 & 2.0 & 1.0 & 94.1 & 1.0 & 11.0 & Log-normal & 0.0 \\
\hline Number of spans in transverse direction & 8.2 & 8.0 & 8.0 & 58.3 & 1.0 & 29.0 & Log-normal & 7.6 \\
\hline Span length in longitudinal direction $(\mathrm{m})$ & 21.5 & 20.0 & 15.0 & 38.4 & 5.5 & 50.0 & Log-normal & 14.4 \\
\hline Span length in transverse direction $(\mathrm{m})$ & 7.6 & 6.5 & 5.0 & 32.9 & 4.2 & 12.5 & Log-normal & 0.0 \\
\hline Column height $(\mathrm{m})$ & 7.7 & 7.0 & 10.0 & 44.3 & 3.0 & 23.0 & Log-normal & 2.9 \\
\hline Column width $(\mathrm{cm})$ & 40.6 & 40.0 & 35.0 & 26.5 & 12.5 & 70.0 & Log-normal & 0.0 \\
\hline Column length $(\mathrm{cm})$ & 56.0 & 50.0 & 40.0 & 42.6 & 30.0 & 150.0 & Log-normal & 10.3 \\
\hline Column height-to-length ratio & 18.1 & 18.8 & 20.0 & 21.9 & 6.9 & 28.9 & Normal & 5.1 \\
\hline Column length-to-width ratio & 1.4 & 1.3 & 1.0 & 45.3 & 1.0 & 3.7 & Log-normal & 0.3 \\
\hline Longitudinal reinforcement ratio (\%) & 1.7 & 1.6 & 1.1 & 41.0 & 0.3 & 3.7 & Log-normal & 50.9 \\
\hline Transverse reinforcement ratio (\%) & 0.3 & 0.2 & 0.2 & 61.9 & 0.1 & 1.0 & Log-normal & 45.1 \\
\hline Corbel span $(\mathrm{mm})$ & 29.4 & 30.0 & 30.0 & 28.4 & 15.0 & 50.0 & Log-normal & 0.1 \\
\hline Concrete strength $(\mathrm{MPa})$ & 30.3 & 25.0 & 25.0 & 32.0 & 12 & 50 & Log-normal & 0.0 \\
\hline
\end{tabular}

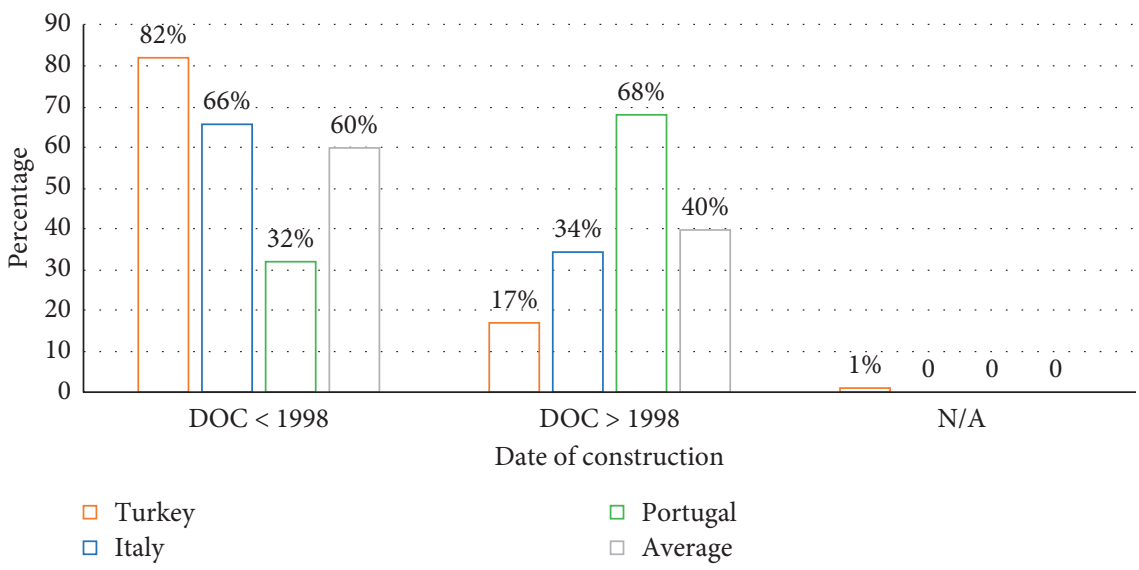

FIgURE 27: Comparison of date of construction (DOC) of precast RC buildings in Portugal and Turkey. 


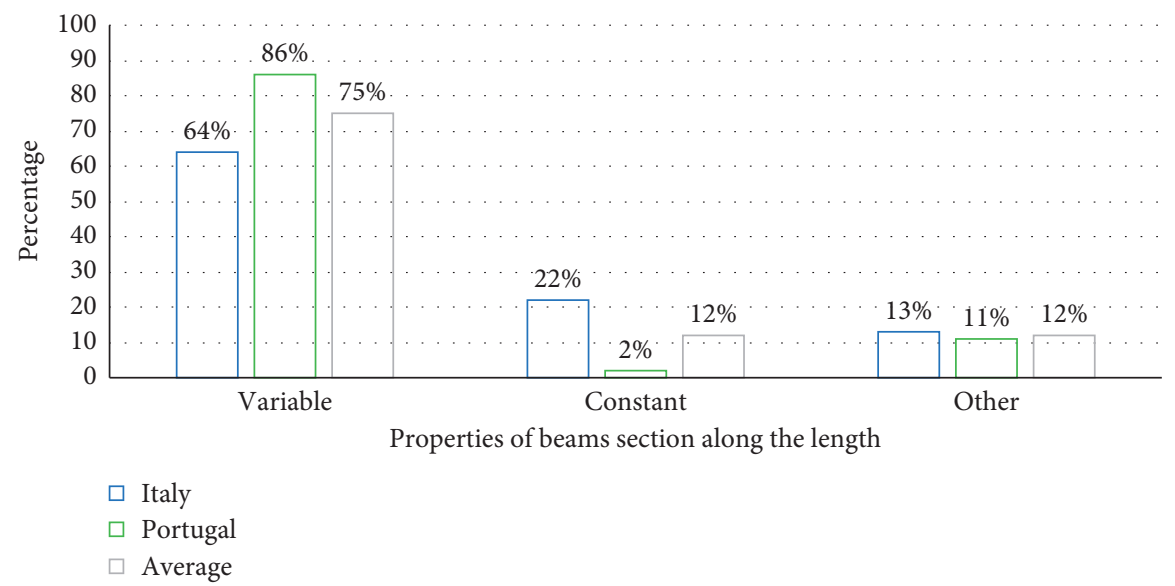

FIgURe 28: Comparison of beams cross-section of precast RC buildings in Portugal and Italy (Emilia-Romagna).

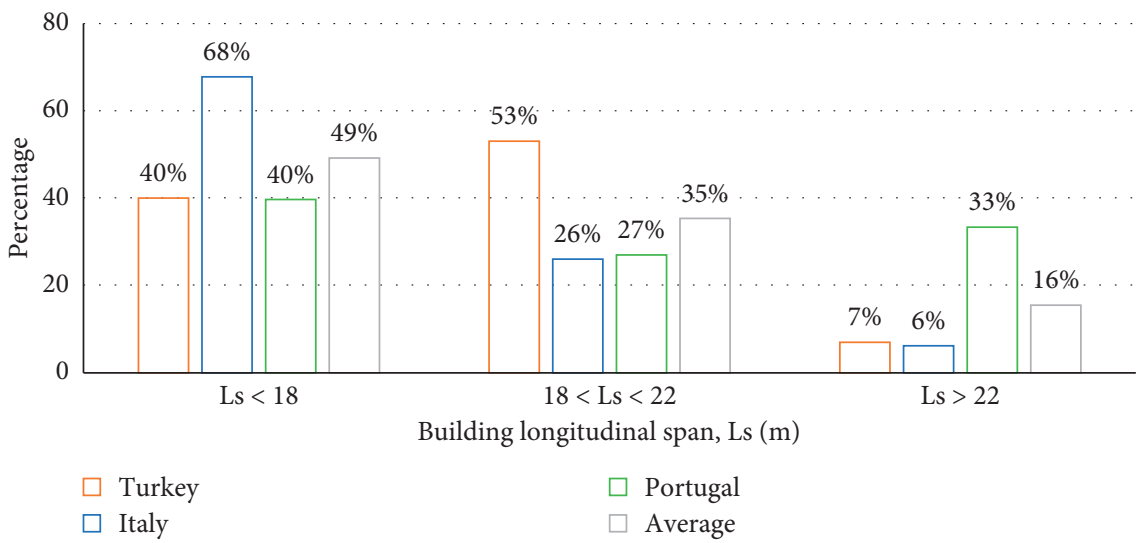

Figure 29: Comparison of longitudinal span (Ls) of precast RC buildings in Portugal, Italy, and Turkey.

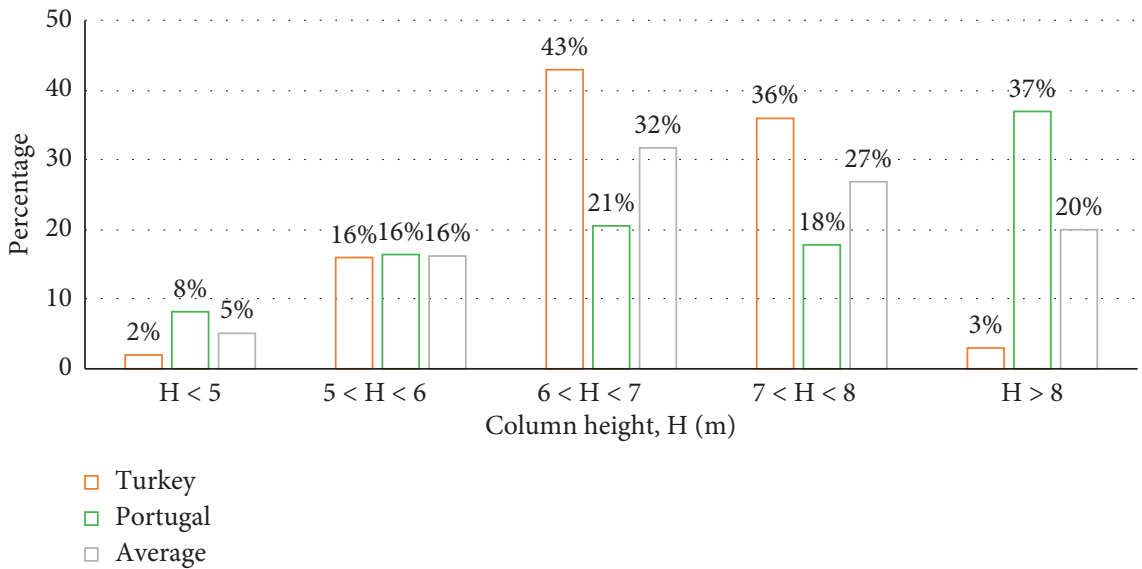

FIGURE 30: Comparison of column height of construction of precast RC buildings in Portugal and Turkey. 


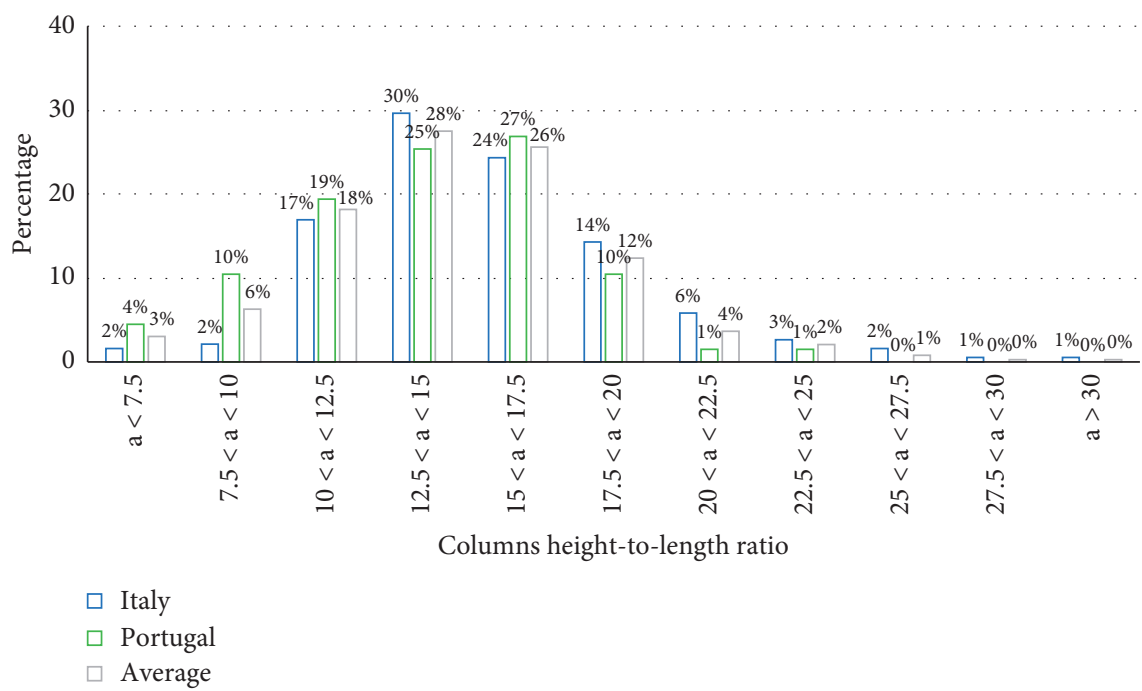

Figure 31: Comparison of height-to-width ratio of precast RC buildings in Portugal and Italy.

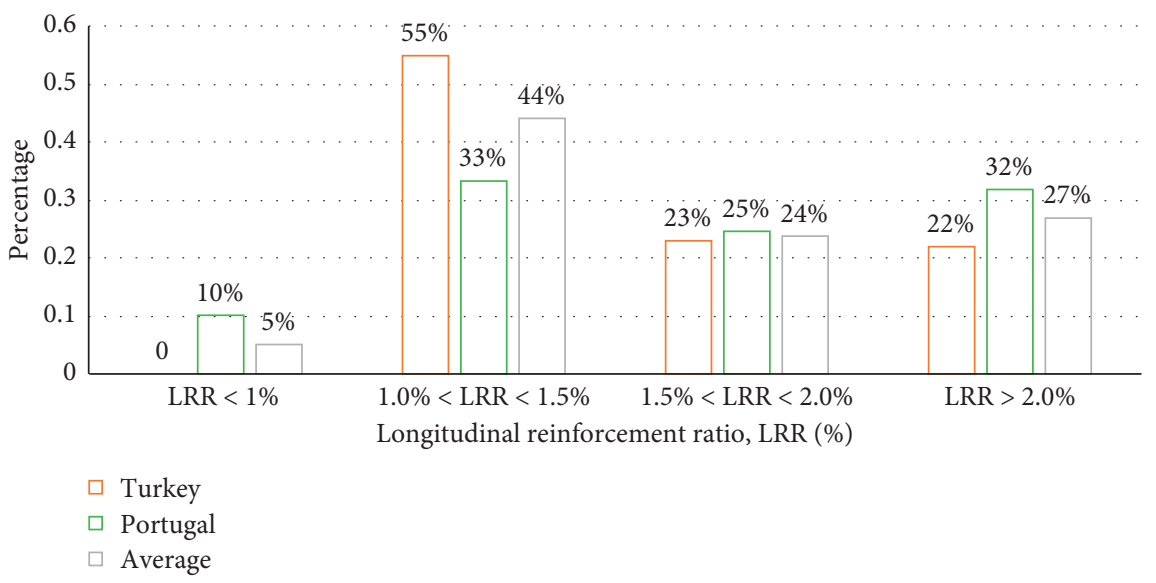

Figure 32: Comparison of longitudinal reinforcement ratio of precast RC buildings in Portugal and Turkey.

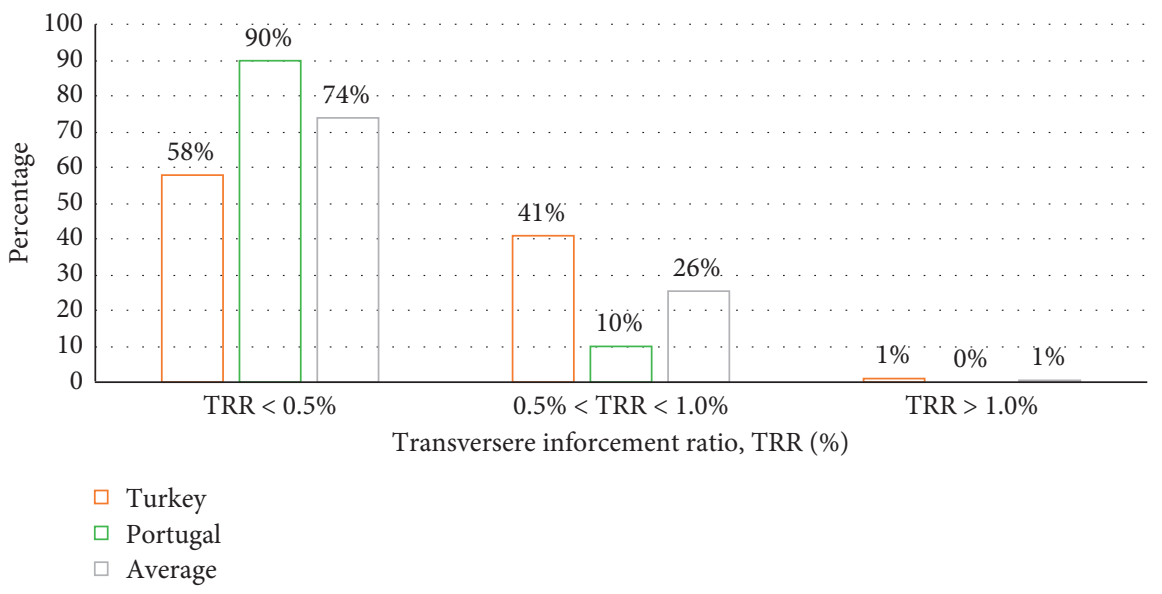

FIgURE 33: Comparison of transverse reinforcement ratio of precast RC buildings in Portugal and Turkey. 
confinement level) and higher shear vulnerability of Portuguese buildings when subjected to seismic loads.

\section{Final Comments}

The determination of the seismic vulnerability of buildings requires the detailed knowledge of their structural properties. For this purpose, a survey was carried out considering a total of 73 design projects of existing buildings. Based on the information collected, it was possible to characterise, from a statistical point of view, the most relevant structural properties of the buildings in Portugal.

Regarding the representativeness of the collected information, the localization of the buildings consulted follows, in a reasonable manner, the actual distribution of the industrial buildings stock. In terms of period of construction, to the authors' knowledge, there is no information available in the literature to assess if the observed concentration in the period after 1990 is consistent with the age of the existing building stock.

Based on the analysis of the information gathered, the most common typology consists of 1-storey framed buildings with beams simply supported on cantilever columns fixed at the base. Generally, in one of the directions, the number of spans is lower and features longer lengths, achieved through beams with variable cross-section. In the other direction, the number of spans is typically higher but features lower lengths; in this case, the beams present constant cross-section, often used to collect the water from the roof. In a small number of cases (approximately 25\%), the buildings feature an intermediate storey that occupies up to $40 \%$ of the total area.

In terms of material properties, an increase in both concrete and steel strength was observed with the year of construction. Overall, the steel grades A400 and A500 appear as the most used reinforcement, whilst for the concrete a concentration of buildings employing concrete with compressive strength (associated with cylinder tests) was observed between 20 and $30 \mathrm{MPa}$.

Regarding the properties of the columns, in addition to the height, cross-section dimensions, and reinforcement ratios (longitudinal and transverse), parameters indicative of the structural robustness such as the height-to-length and length-to-width ratios are also analysed. Additional characteristics relevant from a seismic point of view are also discussed in this document, namely, the type of cladding systems and beam-to-column connection details, including corbel spans and dowel properties.

In summary, the outcome of this study identifies the most conventional typologies of precast RC buildings in Portugal as well as the statistics associated with the most relevant structural parameters. The information provided is essential to estimate the seismic vulnerability of precast $\mathrm{RC}$ buildings and consequently estimate the seismic risk associated with a relevant portion of the industrial building park. Finally, the properties of the Portuguese buildings were compared with other studies carried out in other Mediterranean countries, namely, in Italy and Turkey. This comparison showed some consistency regarding the most conventional typologies. However, it was observed that the Portuguese buildings appear to be relatively taller with longer beam spans and, perhaps more importantly, present a relatively lower transverse reinforcement ratio in the columns.

Despite being merely indicative and considering the poor behaviour of precast buildings in recent earthquakes in Italy and Turkey, this comparison raises some questions regarding the seismic safety of the RC precast building stock in Portugal. Additional studies are thus required to assess in more detail the seismic vulnerability of these structures. The statistical data made available in the present work is of paramount importance to realistically characterise the Portuguese building stock and conduct more detailed seismic risk studies.

\section{Data Availability}

The data obtained are based on real projects. The statistical analysis reported can be used; however, the project details are not available due to data protection issues.

\section{Conflicts of Interest}

The authors declare that they have no conflicts of interest that could have appeared to influence the work reported in this paper.

\section{Acknowledgments}

This work was financially supported by Project POCI-010145-FEDER-028439-“SeismicPRECAST: Seismic Performance ASSessment of existing Precast Industrial Buildings and Development of Innovative Retrofitting Sustainable Solutions" funded by FEDER funds through COMPETE2020-ProgramaOperacionalCompetitividade e Internacionalização (POCI) and by national funds (PIDDAC) through FCT/MCTES. The fourth author acknowledges FCT (Fundação para a Ciência e Tecnologia) for the Ph.D. grant with reference SFRH/BD/139723/2018.

\section{References}

[1] A. Braconi, "Prefabricated steel structures for low-rise buildings in seismic areas (Precasteel)," Brussels, 2013, https://op.europa.eu/ en/publication-detail/-/publication/fd7658c8-192e-4eea-ad6dda916abd4af0.

[2] D. Bellotti, "Capannoni monopiano prefabbricati: distribuzione proba- bilistica dei sistemi e sottosistemi strutturali dagli anni sessanta ad oggi single-storey precast buildings: probabilistic distribution of structural systems and subsystems from the sixties," Progett Sismica, vol. 5, no. 3, pp. 41-70, 2014.

[3] S. M. Senel and A. H. Kayhan, "Fragility based damage assessment in existing precast industrial buildings: a case study for Turkey," Structural Engineering and Mechanics, vol. 34, no. 1, pp. 39-60, 2010.

[4] FFMS, "Número de empresas de industrias transformadoras," Pordata, https://www.pordata.pt/, 2017.

[5] C. Chastre and V. Lúcio, "Estruturas pré-moldadas no mundoaplicações e Comportamento Estrutural," Fundação da 
Faculdade de Ciência e Tecnologias da Universidade NOVA de Lisboa, Lisbon, Portugal, 2012.

[6] RSA, "Regulamento de segurança e acções para estruturas de edifícios e pontes-decreto-lei n. ${ }^{\circ}$ 235/83," 1983.

[7] A. Furtado, C. Costa, A. Arêde, and H. Rodrigues, "Geometric characterization of Portuguese RC buildings with masonry infill walls," European Journal of Environmental and Civil Engineering Impact Factor, vol. 20, no. 4, pp. 396-411, 2015.

[8] R. Sousa, A. Costa, A. C. Campos Costa, X. Romão, and P. Candeias, "Caracterização do comportamento sísmico de edifícios de betão armado representativos do edificado português sem dimensionamento sismorresistente," Revista Portuguesa de Engenharia de Estruturas, pp. 105-114, 2017.

[9] REBA, Regulamento de Estruturas de Betão Armado. DecretoLei N. ${ }^{\circ}$ 47723, REBA, Lisboa, Portugal, 1967.

[10] REBAP, Regulamento de Estruturas de Betão Armado e PréEsforçado. Decreto-Lei N. ${ }^{\circ}$ 349-C/83, REBAP, Lisboa, Portugal, 1983.

[11] A. Belleri, E. Brunesi, R. Nascimbene, M. Pagani, and P. Riva, "Seismic performance of precast industrial facilities following major earthquakes in the Italian territory," Journal of Performance of Constructed Facilities, vol. 29, no. 5, p. 04014135 , 2015.

[12] G. Magliulo, M. Ercolino, C. Petrone, O. Coppola, and G. Manfredi, "The Emilia earthquake: seismic performance of precast reinforced concrete buildings," Earthquake Spectra, vol. 30, no. 2, pp. 891-912, 2014.

[13] D. A. Bournas, P. Negro, and F. F. Taucer, "Performance of industrial buildings during the Emilia earthquakes in Northern Italy and recommendations for their strengthening," Bulletin of Earthquake Engineering, vol. 12, no. 5, pp. 2383-2404, 2014.

[14] D. Beilic, C. Casotto, R. Nascimbene, D. Cicola, and D. Rodrigues, "Seismic fragility curves of single storey RC precast structures by comparing different Italian codes," Earthquakes and Structures, vol. 12, no. 3, pp. 359-374, 2017.

[15] M. Deyanova, S. Pampanin, and R. Nascimbene, "Assessment of silgle-storey precast concrete industrial buildings with hinged beam-column connections with and without dowels," in Proceedings of the Second European Conference on Earthquake Engineering and Seismology, pp. 1-14, Istanbul, Turkey, August 2014.

[16] C. Casotto, V. Silva, H. Crowley, R. Nascimbene, and R. Pinho, "Seismic fragility of Italian RC precast industrial structures," Engineering Structures, vol. 94, pp. 122-136, 2015. 